\title{
Expert opinion on the recognition, diagnosis and management of children and adults with Fabry disease: a multidisciplinary Turkey perspective
}

Fatih Ezgu ${ }^{1 *}$ (D) Erkan Alpsoy ${ }^{2}$, Zerrin Bicik Bahcebasi ${ }^{3}$, Ozgur Kasapcopur $^{4}$, Melis Palamar ${ }^{5}$, Huseyin Onay ${ }^{6}$, Binnaz Handan Ozdemir ${ }^{7}$, Mehmet Akif Topcuoglu ${ }^{8}$ and Omac Tufekcioglu ${ }^{9}$

\begin{abstract}
This consensus statement by a panel of Fabry experts aimed to identify areas of consensus on conceptual, clinical and therapeutic aspects of Fabry disease (FD) and to provide guidance to healthcare providers on best practice in the management of pediatric and adult patients with FD. This consensus statement indicated the clinical heterogeneity of FD as well as a large number of pathogenic variants in the GLA gene, emphasizing a need for an individualized approach to patient care. The experts reached consensus on the critical role of a high index of suspicion in symptomatic patients and screening of certain at-risk groups to reveal timely and accurate diagnosis of FD along with an increased awareness of the treating physician about the different kinds of pathogenic variants and their clinical implications. The experts emphasized the crucial role of timely recognition of FD with minimal delay from symptom onset to definite diagnosis in better management of FD patients, given the likelihood of changing the disease's natural history, improving the patients' quality of life and the prognosis after enzyme replacement therapy (ERT) administered through a coordinated, multidisciplinary care approach. In this regard, this consensus document is expected to increase awareness among physicians about unique characteristics of FD to assist clinicians in recognizing FD with a well-established clinical suspicion consistent with pathogenic variants and gender-based heterogeneous clinical manifestations of FD and in translating this information into their clinical practice for best practice in the management of patients with FD.
\end{abstract}

Keywords: Fabry disease, Expert panel, Awareness, Screening, Diagnosis, Pathogenic variants, Heterogeneity, Management, Multidisciplinary approach

\section{Background}

Fabry disease (FD; OMIM \#301500) is an X-linked lysosomal storage disorder caused by deficiency in the lysosomal enzyme $\alpha$-galactosidase A ( $\alpha$-Gal A), and

\footnotetext{
*Correspondence: fezgu@gazi.edu.tr

${ }^{1}$ Department of Pediatrics, Division of Pediatric Metabolism and Division of Pediatric Genetics, Gazi University Faculty of Medicine, 06560 Ankara, Turkey

Full list of author information is available at the end of the article
}

consequent accumulation of glycosphingolipids, such as globotriaosylceramide (Gb3) and its deacylated derivative globotriaosylsphingosine (lyso-Gb3) within tissues that progressively affect multiple organ systems [1-3].

Fabry Disease is considered as a multi-systemic disorder with progressive neurological, renal, cardiac, ocular and dermatological manifestations [1, 4]. However, even if peculiar signs and symptoms arise in childhood, there is a significant diagnostic delay of up to 20 years from symptom onset $[1,5-8]$. This is 
probably due to the lack of awareness and to the wide spectrum of clinical presentations especially in females $[1,5-8]$. Therefore, to recognize the signs and symptoms of FD is closely related to the disease awareness among pediatricians, pediatric metabolic experts, pediatric geneticists, cardiologists, neurologists, dermatologists, nephrologists, trained pathologists, and ophthalmologists [4]. Notably, once the diagnosis is made, it possible to change the disease's natural history and progression as well as to improve patients' quality of life (QoL) via treatment $[6,9,10]$.

The frequency of inborn metabolic diseases in Turkey is considerably high in general, probably related to the high rate of consanguineous marriages [11]. In accordance with worldwide statistics on an increased awareness of FD among physicians since the disease has become treatable with enzyme replacement therapy (ERT) [12, 13], the heightened awareness about FD is also evident in Turkey, especially after the availability of ERT [14]. Accordingly, in first screening study done in Turkey carried out in a group of male hemodialysis patients using plasma $\alpha$-Gal A test, authors reported the prevalence of FD to be $0.24 \%$ [15]. Afterwards, data from the largest screening study in Turkey that used DBS method for both males and females, along with family screening of the index cases, revealed the prevalence of FD to be $0.17 \%$ in all dialysis patients and to be $0.32 \%$ in male dialysis patients [16].

However, being a rare disease with a long natural history, FD poses several problems for evidence-based medicine such as difficulty in conducting randomized clinical trials in terms of small sample size, wide clinical spectrum especially in females, unfeasibility of a very long follow-up needed to record end-points, a high probability of enrolling patients with already advanced disease at the recruitment period and ethical problems related to placebo-controlled design given the availability of therapy [17]. Accordingly, along with the considerable variability in the clinical expression of FD and the difficulties in diagnosing the disease, there is a considerable challenge for clinicians in the decision-making process while managing patients with FD due to limited availability of evidence-based solid criteria on therapeutic and prognostic algorithms [6].

Therefore, this review by a panel of Fabry experts aimed to provide guidance to healthcare providers on best practice in recognition, diagnosis, and management of pediatric and adult FD patients through a practical and implementable document with a comprehensive framework addressing the conceptual, clinical, and therapeutic aspects of FD mainly focusing on the general approach in Turkey.

\section{Methods}

The present panel of FD experts from ten different specialties involved in the management of patients with FD including nephrology, cardiology, neurology, dermatology, ophthalmology, pediatric metabolic diseases, pediatric genetics, pediatric rheumatology, medical genetics, and pathology convened in Istanbul, Turkey to develop a consensus opinion on the conceptual, clinical and therapeutic aspects of FD from the Turkey's perspective. The participating Fabry experts with at least 15 years of experience in dealing with FD in different provinces of the main geographical regions of Turkey were informed about the study via e-mail by the sponsor and then participated in the consecutive meetings to achieve the proposed consensus. The panel critically analyzed recommendations from existing guidelines and data from systematic reviews, meta-analyses and literature review of articles published on FD in pediatric and adult populations and agreed on a series of statements supported by scientific evidence and expert clinical opinion to assist healthcare providers on best practice in recognition, diagnosis, and management of FD. The development of the consensus document was also guided by a number of key questions regarding specialty-based diagnostic criteria, diagnostic challenges, high risk individuals, biomarkers as well as optimal management and follow up of patients. The proposed consensus planned to provide a practical and implementable guidance document addressing FD in terms of (a) definition and epidemiology, (b) phenotypes and clinical manifestations according to patient age (early, late) and specific organ involvement (renal, cardiac, nervous system, ocular, dermatological), (c) diagnosis and biomarkers, (d) clinical suspicion, screening and genetic counselling, (e) treatment (ERT, adjuvant therapy), and (f) role of multidisciplinary approach in evaluation and management of the disease.

\section{Phenotypes and clinical manifestations}

FD (Online Mendelian Inheritance in Man [OMIM] \#301500), is a progressive $\mathrm{X}$-linked lysosomal storage disorder, caused by deficiency of lysosomal enzyme $\alpha$-Gal A (Enzyme Commission [EC] number 3.2.1.22) due to pathogenic variants in the encoding GLA gene (OMIM \#300644; HGNC 4296) [1, 2, 4, 18]. This results in loss of function of the enzyme and deposition of glycosphingolipids, such as globotriaosylceramide (Gb3) and its deacylated derivative globotriaosylsphingosine (lysoGb3), within lysosomes in virtually all cell types including capillary endothelial cells, renal cells (podocytes, tubular cells, glomerular endothelial, mesangial, and interstitial 
cells), cardiac cells (cardiomyocytes and fibroblasts) and nerve cells $[1,2,4,19]$.

The primary disease process, through this continuous deposition, starts as early as during the fetal stage of development, whereas unlike to many other lysosomal storage diseases, most patients remain clinically asymptomatic during the very first years of life until occurrence of first symptoms at ages of 3 to 10 years, and generally a few years later in girls than in boys [1,20-22].

With advancing age, significant lysosomal and cellular dysfunction probably trigger a cascade of events (i.e. cellular death, inflammation, small vessel injury, oxidative stress and tissue ischemia) and results in development of a multisystem disorder via progressive damage to the vascular endothelia, particularly of small vessels, affecting multiple vital organ systems including the heart, nervous system, and kidneys [1, 4, 23]. Accordingly, affected patients are at high risk of developing fibrotic cardiac disease resulting in rhythm and conduction disturbances, progressive hypertrophic cardiomyopathy ( $\mathrm{HCM}$ ), progressive proteinuric kidney disease, a small-fiber neuropathy and mostly ischemic cerebrovascular stroke [23-26].

The estimated incidence of FD in the general population is 1 in 117,000 and 1 in 40,000 males [4, 10,27], while this has been considered a significant underestimation given the under-recognition of symptoms and delayed or missed diagnoses $[4,10]$. Accordingly, newborn screening studies revealed overall incidence estimates of 1 in $\sim 1250-3100$ males $[28,29]$, although a prevalence of around 1 in 8000 is also considered more likely when benign variants of the GLA gene have been excluded $[1,4]$.

The natural course of FD indicates that the mean survival of patients is about 55 years for males and about 70 years for females with an $\sim 17$-year and 5-year shortened life span, respectively [30,31]. This is important given that once a diagnosis is made, the disease can be effectively and safely controlled with treatment $[9,10$, 32].

FD has two major phenotypes including "classic" and "late onset" subtypes $[8,13,33]$. The classic (typical) phenotype is characterized by little or no residual $\alpha-\mathrm{Gal} A$ enzyme activity and onset with the typical early symptoms (i.e. acroparesthesias, angiokeratoma, hypohidrosis and/or a characteristic corneal dystrophy) during childhood/adolescence, particularly in males. "Non-classical" form is also referred as "later-onset" form and includes "cardiac" or "renal" variants with no/minimal involvement of other organs. The clinical manifestations in heterozygous females range from asymptomatic throughout a normal life span to as severe as affected males. Variation in clinical manifestations is attributed to X-chromosome inactivation pattern. With advancing age, the progressive deposition of glycosphingolipids lead to progressive multi-system involvement that results in renal failure, $\mathrm{HCM}$, and/or cerebrovascular disease [2, 13, 24, 25, 33]. The late onset (atypical) phenotype is typically less severe with a significant residual $\alpha$-Gal A activity in males, who remain clinically asymptomatic until the 4-7th decades of life, when they develop progressive organ damage and present with a cardiomyopathy or end-stage renal disease (ESRD) and/or cerebrovascular insult $[1,8,12,13,34$, 35].

In fact, the age of onset of symptoms, the extent of organ involvement, and prognosis of FD depend both on the underlying degree of $\alpha$-Gal A deficiency and the gender of the patient $[2,36,37]$. Males with higher residual enzyme activity tend to have later onset disease with predominantly single organ forms, while females tend to have milder and slowly progressing disease phenotypes as well as a wider spectrum of disease severity (ranging from asymptomatic to severely affected phenotype) than males [2, 5, 36, 37].

This variation in the phenotype and disease course among female patients, that ranges from being asymptomatic throughout a normal life span to as severe as many affected males, has been attributed to the severity of the pathogenic variants and X-chromosome inactivation [5, $38,39]$. More severely affected females are more likely to have the X-chromosome with the GLA wild-type gene inactivated and the $\mathrm{X}$-chromosome carrying the pathogenic variant remaining expressed in the affected organs $[8,22,25,33]$.

Besides these factors, a recent study from Turkey suggested that co-existent factors (such as increased lipoprotein (a), homocysteine, total and low density cholesterol and antithrombin 3 levels; prothrombin p.G20210A and factor V Leiden pathogenic variants) or diseases (such as rheumatologic diseases or celiac disease) could significantly modify the phenotype in both females and males should be considered as a part of initial work-up [14].

FD is further characterized by a large number of pathogenic variants in the GLA gene, including variants associated with the classic phenotype, later onset phenotype and benign variants and variants of uncertain significance (VUS) [1, 2, 40, 41].

\section{Clinical manifestations specific to age Early signs and symptoms: FD in pediatric and adolescent age}

In classic $\mathrm{FD}$, the first symptoms that may emerge in childhood or early adolescence are skin abnormalities (angiokeratomas), corneal deposits (cornea verticillata), microalbuminuria and/or proteinuria, and symptoms related to autonomic nervous system involvement including acroparesthesia (chronic neuropathic pain), diffuse 
episodic pain crises (Fabry crises), and sweating abnormalities (anhidrosis or hypohidrosis) [1, 39, 42]. Tinnitus may be an early symptom and hearing loss has been reported in children, while chronic fatigue and difficulty gaining weight may also frequently occur, particularly during adolescence [1]. Early signs of cardiac (shortened PR interval, arrhythmias, chronotropic incompetence, aortic dilation at the Valsalva sinuses and mild valvular insufficiency) and cerebrovascular abnormalities (cerebral small vessel involvement) may also be detectable during adolescence in both genders (Table 1) [43, 44].

Importantly, these symptoms, albeit not accompanied with major organ dysfunction, can be significant cause of morbidity by negatively affecting physical, school and social performances of children [45].

\section{Late/advanced signs and symptoms: FD in adulthood}

In adulthood, with disease progression, patients are at significant risk of ESRD necessitating early dialysis and other renal replacement treatments and the development of serious cardiovascular [i.e. left ventricular hypertrophy (LVH), HCM, cardiac arrhythmias, valvular disease] and cerebrovascular complications [i.e. cerebral white matter lesions (CWMLs), transient ischemic attacks (TIAs), ischemic strokes] that can cause premature death $[1,39,42]$. In addition, many adults continue to suffer from debilitating pain and some adult patients display a unique neuropsychiatric phenotype, characterized by subtle movement impairment and depression, resulting in reduced QoL (Table 1) $[1,42,46]$.

Fabry Disease can have overlapping signs and symptoms with other disorders such as Familial Mediterranean Fever (FMF), juvenile systemic lupus erythematosus and celiac disease which are frequently seen in Turkey. Fabry Disease should also be considered for patients with a preliminary/confirmed diagnosis of such disorders as the real etiologic/co-existent disease [47-49].

Table 1 Signs and symptoms of Fabry disease [1, 39, 42-46]

\begin{tabular}{|c|c|c|}
\hline \multirow[t]{2}{*}{ Organ system } & \multicolumn{2}{|l|}{ Clinical manifestations (signs/symptoms) } \\
\hline & Pediatric & Adult \\
\hline \multirow[t]{7}{*}{ Peripheral neuropathy } & Neuropathic pain (Fabry crises) & Present or past experience of neuropathic pain \\
\hline & Hypohidrosis, heat intolerance & Hypohidrosis, heat intolerance \\
\hline & Hearing loss, vertigo & Hearing loss, vertigo \\
\hline & Nausea, vomiting, diarrhea & Nausea, vomiting, diarrhea \\
\hline & Abdominal pain & Abdominal pain \\
\hline & Postprandial bloating and pain, early satiety & Postprandial bloating and pain, early satiety \\
\hline & Difficulty gaining weight & Difficulty gaining weight \\
\hline \multirow[t]{4}{*}{ Cerebrovascular involvement } & Cerebral microvascular ischemic involvement & Significant white matter lesions \\
\hline & & Transient ischemic attacks \\
\hline & & Ischemic strokes \\
\hline & & Neuropsychiatric phenotype \\
\hline \multirow[t]{4}{*}{ Renal } & Microalbuminuria, proteinuria & Albuminuria overt proteinuria \\
\hline & & Progressive chronic kidney disease \\
\hline & & Kidney failure \\
\hline & & End-stage renal disease necessitating renal replacement treatments \\
\hline \multirow[t]{5}{*}{ Cardiac } & Impaired heart rate variability & Left ventricular hypertrophy \\
\hline & Arrhythmias & Hypertrophic cardiomyopathy \\
\hline & ECG abnormalities (shortened PR interval) & Cardiac arrhythmias \\
\hline & Mild valvular insufficiency & Valvular disease \\
\hline & Aortic dilatation at Valsalva sinuses & \\
\hline \multirow[t]{4}{*}{ Dermatological } & Angiokeratomas & Angiokeratomas \\
\hline & Sweating abnormalities (hypohidrosis) & Linear telangiectasia \\
\hline & & Lymphedema \\
\hline & & Hypotrichosis \\
\hline \multirow[t]{2}{*}{ Ocular } & $\begin{array}{l}\text { Corneal deposits (cornea verticillata) and } \\
\text { lenticular opacities }\end{array}$ & Corneal deposits (cornea verticillata) and lenticular opacities \\
\hline & Vasculopathy (conjunctiva, retina) & Vasculopathy (conjunctiva, retina) \\
\hline
\end{tabular}




\section{Clinical manifestations specific to organ involvement \\ Renal involvement}

Fabry nephropathy is related to progressive decrease in renal function with onset of deposition of Gb3 in almost all renal cell types (i.e. vascular endothelial cells, vascular smooth muscle cells, mesangial cells, interstitial cells, podocytes, and distal tubular epithelial cells) as early as during fetal development $[8,50]$. Increase in microalbuminuria and proteinuria are the initial manifestations of renal impairment that occur as early as 10 years of age or earlier, while a decline in glomerular filtration rate (GFR) is seen starting from the adolescence in classic patients. $[1,51]$.

With progressive chronic kidney disease (CKD) including albuminuria and overt proteinuria in the second decade of life [52-54], renal pathology increases in severity and chronic renal insufficiency and ESRD develop ultimately in the $3-5$ th decades and $4-5$ th decades of life, respectively $[1,8,55,56]$.

The dialysis is initiated due to ESRD among male patients with FD in the 4-5th decades of life [57] and kidney dysfunction is less prevalent and less severe among female heterozygous patients, while some cases of ESRD among heterozygous females have also been reported [58].

\section{The consensus statement on Fabry-specific renal involvement}

- Laboratory investigations of kidney function that should be carried out in every patient include serum creatinine, cystatin C, estimated GFR (e-GFR), urinary protein, albumin and/or microalbumin excretion and urinary sodium excretion [59]. Assessment of proteinuria and GFR can be used for the staging of CKD, while urinary protein excretion is strongly and independently associated with renal disease progression in FD, regardless of the gender $[1,60,61]$.

- Light microscopy in biopsy specimens from kidney shows the accumulation of sphingolipids as PASpositive Sudan-positive intra-lysosomal inclusions viewed under polarized light [62]. However, this does not usually contribute a great deal to diagnosis given that exposure of biopsy material to lipid-dissolving materials in preparation for light microscopic evaluation results in non-specific findings (foamy podocytes) likely to be observed in any disease associated with nephrotic range proteinuria (Fig. 1).

- Electron microscopy-based ultrastructural studies of kidney biopsies can reveal lysosomal storage in a variety of kidney cellular types, based on identification of the inclusions as whorled layers of alternating

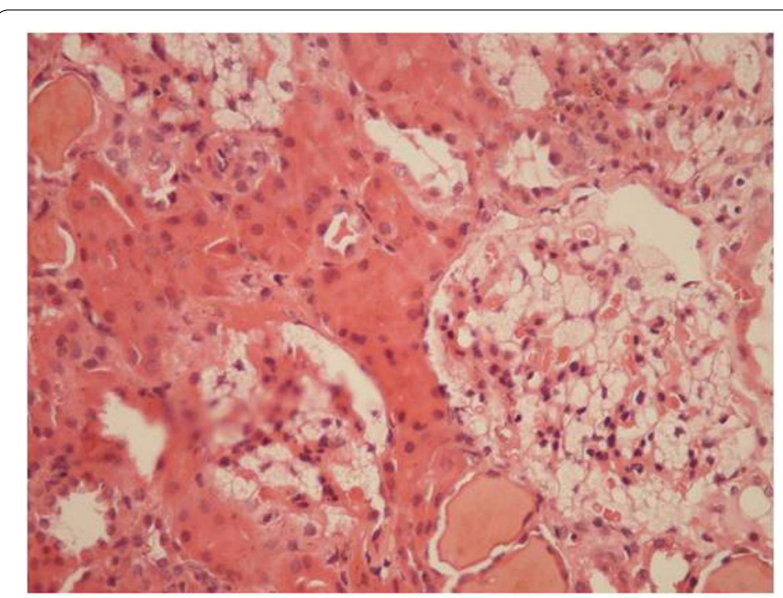

Fig. 1 Pathologic findings of renal involvement of Fabry disease in kidney biopsy, light microscopy (Hematoxylin Eosin staining, X400 magnified)

dense and pale material ('zebra bodies' or myelin figures) [1].

- Importantly, when electron microscopy is not available, preparation of semi-thin (1 micron) sections with osmium tetroxide and glutaraldehyde fixation and toluidine blue or Masson's trichrome staining is considered to allow diagnosis with detection of zebra bodies when viewed under polarized light without using electron microscopy [1].

- Given that potentially irreversible changes to glomeruli, interstitial tubules and vascular structures can be observed in renal biopsy specimens even before the first appearance of microalbuminuria in a child, the histological changes are considered to be an early indicator of renal damage and diagnostic as well as prognostic indicators in FD [63].

- Histological studies should not routinely be performed for the diagnosis of FD, while a biopsy of the affected organ for a histological study with electron microscopy is necessary in cases of suspected FD having indefinite enzyme and/or genetic test (especially VUS) results [6]. In addition it should also be noted that, acquired metabolic disorders, such as the one induced by chloroquine therapy, may result in storage of ultrastructurally similar inclusions in many of the same cells as FD, leading to erroneous interpretation [64].

\section{Cardiac involvement}

Cardiac manifestations occur in $40-60 \%$ of FD patients with similar spectrum in the classic and the late onset cardiac phenotype including LVH, conduction 
abnormalities, bradycardia and chronotropic incompetence, supraventricular and ventricular tachyarrhythmia, myocardial fibrosis, valve disease, aortic dilation at Valsalva sinuses and microvascular dysfunction [65-67].

Right ventricular hypertrophy with diastolic dysfunction is also considered to be common in FD, being responsible for clinical features such as reduced exercise capacity, organomegaly and lymphedema in patients with preserved left ventricle function [68]. According to data from the Fabry Registry, heart failure occurs in 3.5\% in men and $2.3 \%$ in women with FD [66], while myocardial fibrosis is a marker for poor prognosis as associated with increased risk of malignant ventricular arrhythmias and sudden cardiac death [69-71].

In FD, men aged $>30$ years and women aged $>40$ years most often present with LVH unexplained by abnormal cardiac loading conditions (i.e. hypertension or aortic stenosis) and usually concentric and non-obstructive [1, 4]. However, sometimes the picture mimics sarcomeric HCM, particularly when isolated, as in the cardiac or late-onset variant of the disease, and cardiologists should therefore be aware of the cardiac variant of FD in case of HCM [1, 4]. Notably, in HCM cohorts, up to $1-3 \%$ of patients have been diagnosed with FD, while the prevalence of $\mathrm{HCM}$ resulting from sarcomeric gene pathogenic variants is reported in $1 / 500-1 / 200$ of the general population, and at least $10 \%$ of $\mathrm{HCM}$ among adults is estimated to have non-sarcomeric origins, arising rather from amyloidosis, FD or mitochondrial diseases, necessitating specific treatments $[4,72]$.

\section{The consensus statement on Fabry-specific cardiac involvement}

- The initial cardiac evaluation should include resting 12-derivation ECG, long-duration electrocardiogram recordings, echocardiography, and late gadolinium and T1 mapping magnetic resonance imaging (MRI) [36]. Abnormalities of a non-hypertrophied inferolateral wall at the base of the left ventricle and low native T1 signal on MRI are evocative [4].

- Diagnosis of LVH is usually made initially by echocardiography to assess the extent and pattern of LVH and evaluation of cardiac dysfunction, which typically combines concentric thickening without left ventricular obstruction and normal LVEF (Fig. 2) [4, 8].

- However, asymmetric septal or apical hypertrophy has also been described, along with sub-aortic obstruction, which may mimic the phenotypical and clinical features of sarcomeric HCM [72-74]. In such cases T1-mapping MRI is useful, given that a low native T1 is specific to FD cardiomyopathy, while very uncommon in HCM due to sarcomere gene pathogenic variants, amyloidosis, or hypertension [75]. Although low native T1 can be also observed in haemochromatosis, this can be eliminated based on low T2* values [74]. Low nativeT1 values of the myocardium secondary to sphingolipid storage are noted in $40 \%$ of patients with FD without LVH and in $>90 \%$ of patients with FD with LVH, indicating T1 mapping a useful test for early detection of cardiac involvement, even in the absence of $\operatorname{LVH}[4,75,76]$.

- Indeed, cardiac MRI is becoming increasingly important for the diagnosis of cardiac involvement in FD, since it is able to identify patients with fibrosis as well as LVH more precisely and T1-mapping MRI and strain echocardiography might be more sensitive for the early detection of the cardiac manifestations of FD (Fig. 3) [72-74].

- Cardiac MRI also offers higher definition of ventricular structures and visualization of the extent of scarring and fibrosis and more reproducible quantification of LVH for serial within-patient assessments, which is important given that in female patients, cardiac fibrosis may be present before LVH (Fig. 3) [36, 77].

- As MRI is widely available in Turkey, an effort should be made to establish referral centers in several regions specialized for the MRI based cardiac evaluation of patients.

\section{Nervous system involvement}

The early peripheral neuropathic hallmarks of FD are frequently followed by cerebrovascular complications and autonomic dysfunction in adulthood [1].

\section{Small-fibre peripheral neuropathy}

The first neurological symptoms of FD occur due to small-fibre peripheral neuropathy and involve a spectrum of manifestation including peripheral neuropathic pain, deficits of thermal sensation and of physiologic pain perception, impaired sweating, GI dysmotility, and other sensory deficits such as hearing loss [36]. In Fabry neuropathy, both myelinated and non-myelinated nerve fibers are reduced. Gb3 accumulation occurs mainly in the dorsal root ganglion neurons and Schwann cell. However, there is also accumulation in the perineurium, vascular smooth muscle cells, fibroblasts, and endothelial cells. As a main mechanism, a dying back neuropathy is thought to be caused by neuronal damage in the dorsal root ganglion. This explains the intraepidermal nerve fiber density reduction well. Another mechanism involved is chronic nerve ischemia [36]. 


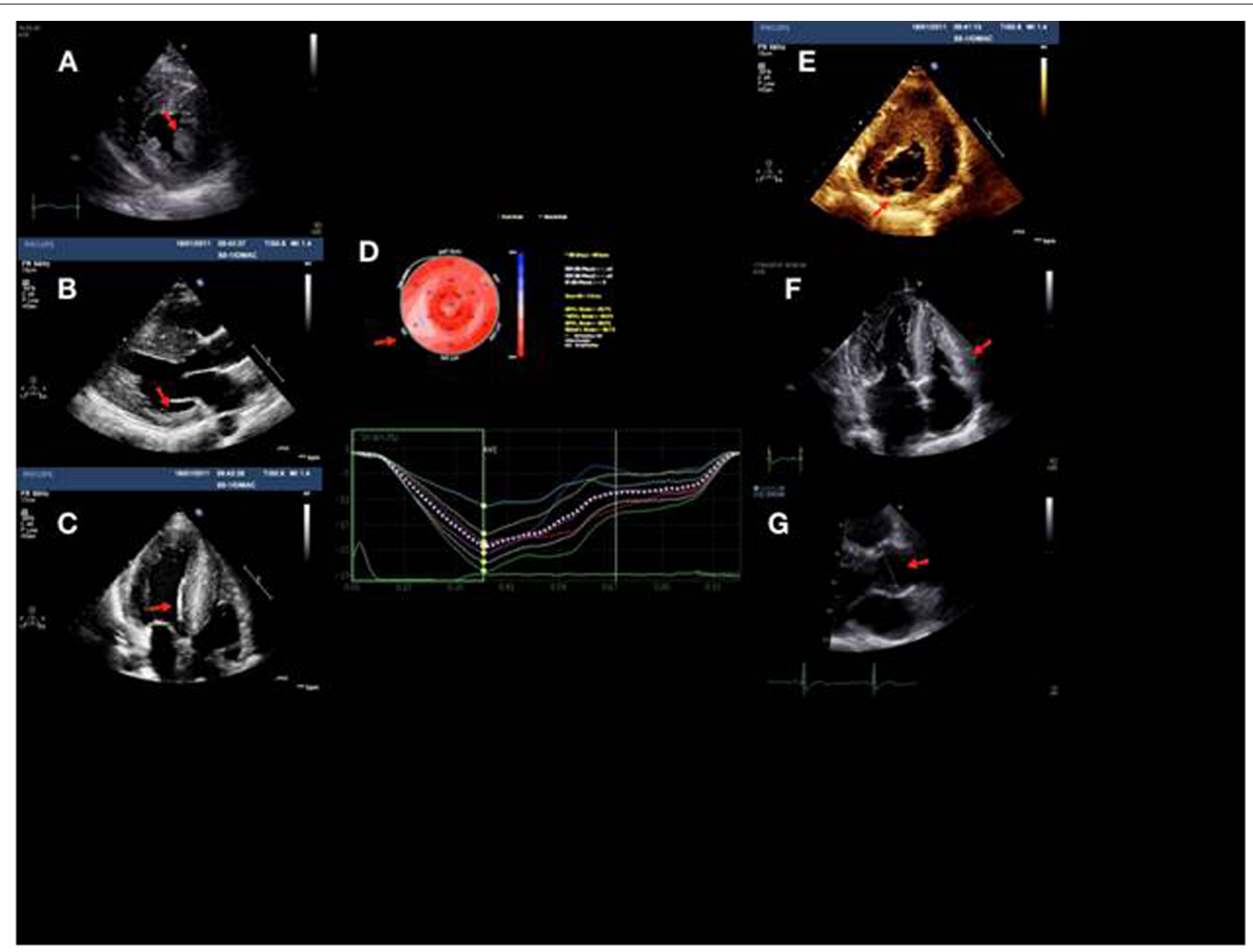

Fig. 2 Echocardiography findings in a patient with Fabry disease. A Hypertrophic papillary muscle, B thinning in inferior and posterior basal walls of the left ventricle in an advanced case, C "Binary sign", D typical "Strain Bull's Eye" in FD, segmenter longitunal strain reduction in infero-basal wall, E increase echogenicity in areas with advanced myocardial fibrosis, $\mathbf{F}$ right ventricular hypertrophy and valvular thickening, $\mathbf{G}$ Aortic dilation at Valsalva sinuses
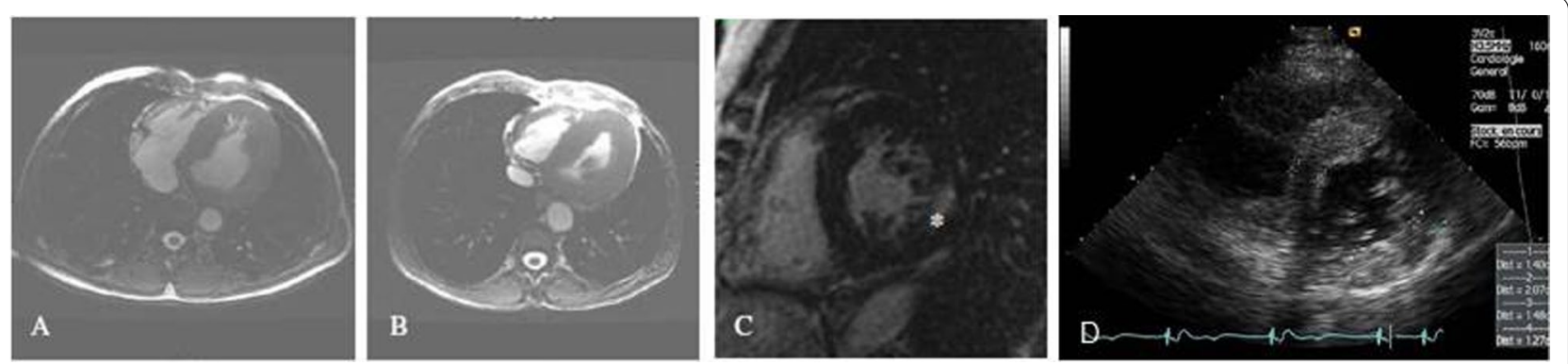

Fig. 3 Cardiac MRI for the assessment of left ventricular hypertrophy and fibrosis. A Left ventricular hypertrophy in a 51-year-old male patient with cerebrovascular involvement and end stage renal disease (dialysis). B Hypertrophic cardiomyopathy in a 56-year-old male patient with arrythmya, leukoareiosis and kidney transplant. C Late enhancement after gadolinium in a 63-years-old female patient with end stage renal disease (dialysis). D Echocardiography: parasternal short axis showing left ventricular hypertrophy. Adapted from Germain Orphanet Journal of Rare diseases 2010, 5:30

\section{Neuropathic pain (Fabry crises)}

Fabry-related neuropathic pain due to small-fibre neuropathy is often the earliest manifestation for children with classical FD (60-80\%) that can occur as early as
3 years of age or less [78], usually occurring at an earlier age in boys than in girls $[79,80]$. The pattern of neuropathic pain in FD is considered to involve evoked pain (allodynia or hyperalgesia), pain attacks, permanent 
(chronic) pain and pain crises along with likelihood of experiencing one or more types concomitantly or a change in the pattern over time $[36,81]$.

\section{The consensus statement on Fabry crises}

The most common presentation of neuropathic pain among FD patients is Fabry pain crises characterized by agonizing burning pain originating in the extremities and radiating inwards to the limbs and other parts of the body, and are often precipitated by rising body temperature due to exercise, fever, or warm ambient environments [1, 39, 58, 82, 83]. An elevated erythrocyte sedimentation rate is commonly noted when the crises are triggered or accompanied by fever, while patients also have a greatly diminished QoL as a result of their pain [1]. In children, other possible causes of small-fiber neuropathy pain that must be ruled out are autoimmune diseases that were usually organ specific and often autoantibody associated including autoimmune thyroiditis, HenochSchönlein purpura, brachial plexitis, type 1 diabetes, post-viral arthritis, immune thrombocytopenic purpura, Crohn's disease, autoimmune trochleitis, Hashimoto's encephalopathy, Sjögren's spectrum disorders, rheumatoid arthritis, rheumatic fever, systemic lupus erythematous, and Raynaud's disease as well as 'growing pains' (a frequent misdiagnosis in children with FD) $[1,47,84,85]$.

Pain may wane in adulthood and it is very important to search for a medical history of Fabry crises in childhood during the first examination of a newly diagnosed adult patient [84].

The prevalence of pain among adults with FD may be up to $80 \%$ and in adults with chronic pain, celiac disease and multiple sclerosis are the most often-cited differential diagnoses, particularly in females. $[1,85,86]$.

\section{Hypohidrosis}

Absence of sweating (anhidrosis) or a decreased ability to sweat (hypohidrosis) with decreased skin impedance has been reported to occur in 53\% of males and $28 \%$ of females with FD due to due to a dysfunction of sympathetic sudomotor fibres [87-89], and considered a significant problem leading to hyperthermia, poor exercise tolerance, and altered fever manifestation [88, 90]. Peripheral sweat production can be measured with quantitative sudomotor axon reflex tests (QSART); sympathetic skin response and heart rate variability are considered less reliable tests [91].

\section{Hearing loss and vertigo}

Auditory and vestibular abnormalities are frequent deficits observed in FD, resulting in a range of symptoms, such as symptomatic (18-55\%) hearing loss (more commonly in classic vs. late onset phenotype) as well as tinnitus and vertigo [92-94]. It is important to know the cause of hearing impairment prior to treatment initiation; audiometry testing and neurological investigations should therefore be carried out at diagnosis and at regular intervals following diagnosis $[1,36,92]$. Recently in a study from Turkey Reflex Decay Test was proposed to be an early indicator of hearing loss due to Fabry Disease [95].

\section{Gastrointestinal dysfunction}

Gastrointestinal (GI) symptoms are common, but underappreciated, manifestation of FD, as some of the earliest and most commonly reported symptoms that usually remain present also during adulthood [1]. Including abdominal pain, bloating, diarrhea, constipation, nausea, and vomiting as well as failure to gain weight [36], GI dysfunction has been associated with deposition of Gb3 in the autonomic ganglia of the bowel and mesenteric blood vessels [96, 97]. In evaluation, use of a validated GI symptom rating scale is important to enable the progression of GI symptoms to be monitored, while other techniques such as endoscopy, scintigraphy, video capsule endoscopy, and intestinal biopsy can also be used to investigate GI symptoms. [36, 97]. Diarrhea-predominant irritable bowel syndrome (IBS) is a differential diagnosis [96].

\section{Cerebrovascular involvement}

Cerebrovascular manifestations in FD patients range from mild to severe and include headache, vertigo/dizziness, transient ischemic attacks, recurrent ischemic strokes, and vascular dementia $[8,98]$. The overall prevalence of ischemic stroke or transient ischemic attack in patients with FD is considered to be $6.9 \%$ for males and $4.3 \%$ for females [99], while prevalence of FD in young patients with cryptogenic ischemic strokes (aged $18-55$ years) is $0.3-1 \%$ $[100,101]$. The 4th decade of life seems to be critical for the progression of white matter hyper-intensities, while no strong correlations have been noted between white matter hyper-intensities and other typical FD phenotype manifestations such as renal or cardiac involvement, pain scores, enzyme activity or lyso-Gb3 levels [102, 103].

The prevalence of basilar artery dolichoectasia (extensive remodeling of the vessel with the morphological changes regarding the diameter, the elongation, and the tortuosity) among the FD population is not well defined, but recent data showed that it could be an early marker of cerebrovascular disease $[36,104]$.

\section{The consensus statement on Fabry-specific cerebrovascular involvement}

- Imaging modalities that can be used to explore cerebrovascular involvement in Fabry patients include brain CT and CT angiography, MRI and MR angi- 
ography in the routine settings, and trans-cranial Doppler (TCD), proton MR spectroscopy (MRS), positron emission tomography (PET) and diffusion tensor imaging in selected cases [1].

- Neuro-radiological findings related to cerebrovascular manifestations of FD include chronic white matter hyper-intensities, the basilar artery dolichoectasia (diameter greater than $4.5 \mathrm{~mm}$ at the midbasilary region), microbleeds, cortical and deep small infarcts (Fig. 4) [1, 98, 105-107].

- Given that all of these neurological manifestations may also accompany other disorders such as hypertension, hyperlipidemia or coagulopathies [8], the younger age of presentation seems to be distinctively characteristic of FD. Morphology and topography of cerebral ischemic lesions and infarcts in FD have no
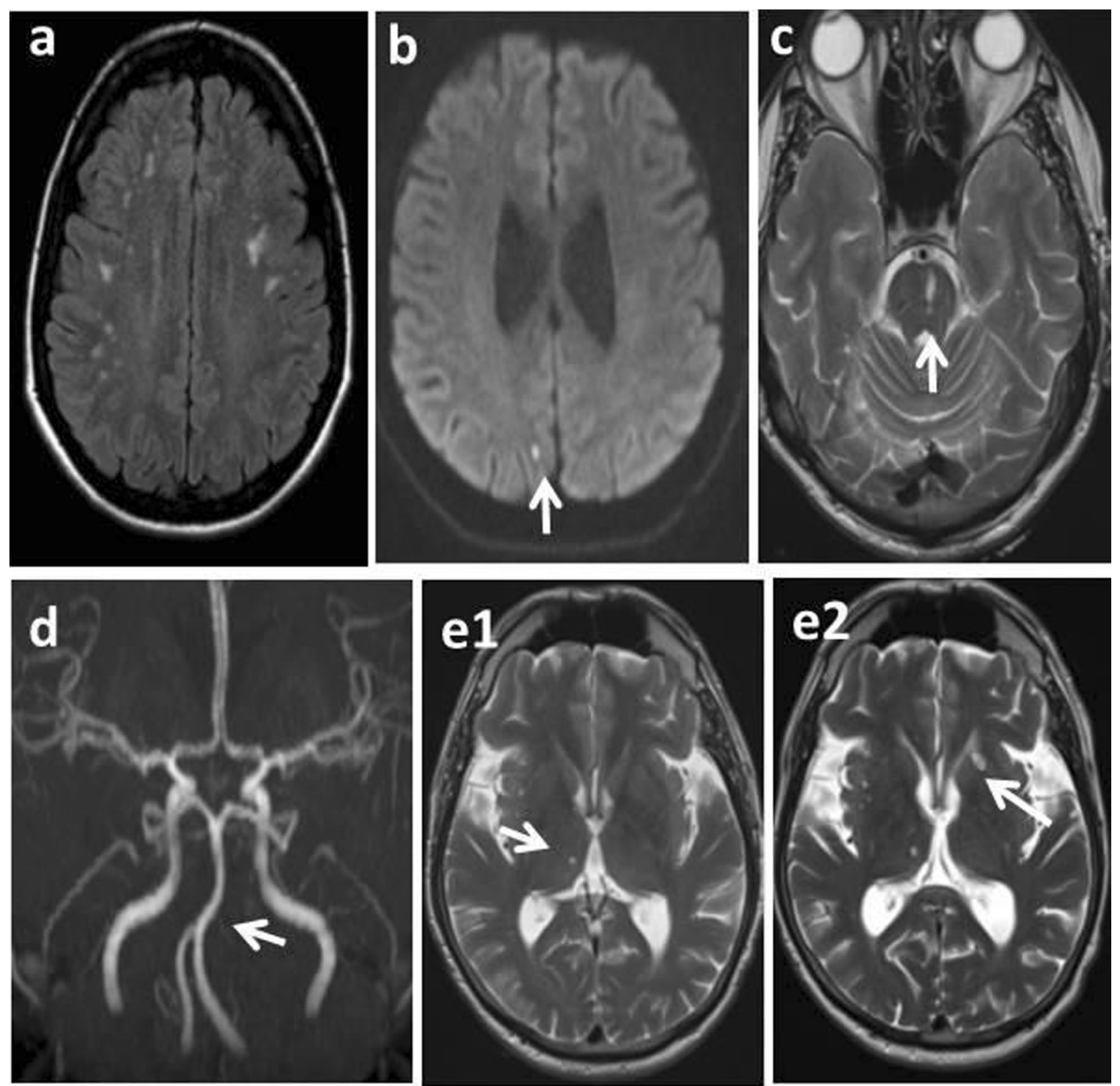

Fig. 4 Neurological involvement in Fabry disease. Spectrum of brain MRI findings in a 51-year-old male patient with Fabry disease: a White matter hyperintense lesions in FLAIR sequence, $\mathbf{b}$ acute small-junctional infarct (arrow) in DWI, c Chronic left midpons perforating infarcts (lacune type, arrow) in T2 weighted images, $\mathbf{d}$ Basilary dolichoarteriopathy (arrow), e1-2) Accumulation of small basal perforating infarcts: e1, right thalamic lesion, e2, emergence of left caudate lesion in 1 year interval 
diagnostic features. Therefore, Fabry should always be considered in all cases of cryptogenic young stroke $($ age $<50)$. However, if young people have thrombotic small vessel disease, Fabry should be among the first priority diagnoses.

- In addition, pulvinar sign (hyperintense appearance of thalamic pulvinar nuclei on T1-weighted images) reflecting the presence of micromineralization has also been considered a highly specific key imaging sign indicative for FD in the presence of other diagnostic clues, being more frequent in male patients with cardiomyopathy and severe kidney involvement. Albeit highly specific, pulvinar sign is a rare finding, at the level of one-fifth of males and case-report among females (Fig. 4) [108-110].

- FD can be misdiagnosed as multiple sclerosis because patients with either disease can present with acute attacks of neuropathic pain in the limbs, especially under conditions of stress, heat, or fatigue and white matter lesions (CMWL) on MRI $[86,111]$. Although the pattern of CWML in FD demonstrates a distribution frequently referred to as "vascular leukodystrophy", variability in appearance due to aging and the temporal lesion load can confound the differential diagnosis [112]. Nevertheless, spinal cord involvement with characteristic neuroradiological findings, when present, is an additional powerful diagnostic element in MS [113]. Usually a careful neuroradiological analysis should be able to distinguish between white matter lesions that are highly suggestive of inflammatory events and MS, from those that are more typical of vasculopathy and FD $[111,113]$.

\section{Ocular involvement}

Ophthalmological manifestations in FD occur as early as the first decade of life and include cornea verticillata, increased vessel tortuosity, Fabry cataracts and symptomatic conjunctival telengiectasias and aneurysm like formations [114, 115].

Cornea verticillata (whorl-like, linear pigmentation in the inferior part of the cornea visible by slit-lamp microscopy) manifests as almost pathognomonic corneal deposits considered among the most common and early of ocular signs, occurring in majority of classical males [114-117]. The observation of typical cornea verticillata is highly predictive for the diagnosis of classic FD, while amiodarone or chloroquine can also produce similar ophthalmological signs (Fig. 5) [114, 117, 118]. Fabry cataract is a posterior capsular cataract with visible whitish spoke-like deposits of granular material and considered a pathognomonic ocular sign of FD [114, 119, 120].

Conjunctival telengiectasias, dilatation and tortuosity, and aneurysm formation of the conjunctival vessels are also considered as relatively common signs in patients with classic FD (Fig. 6). Dry eye syndrome is also one of the frequent symptoms in FB and should be monitored and treated if needed [114]. Mild to marked increased tortuosity of the retinal vessels are also observed in patients with FD (Fig. 7) [116, 120].

Cilioretinal artery occlusion and anterior ischemic optic neuropathy were also reported in a female patient with Fabry Disease from Turkey [121].
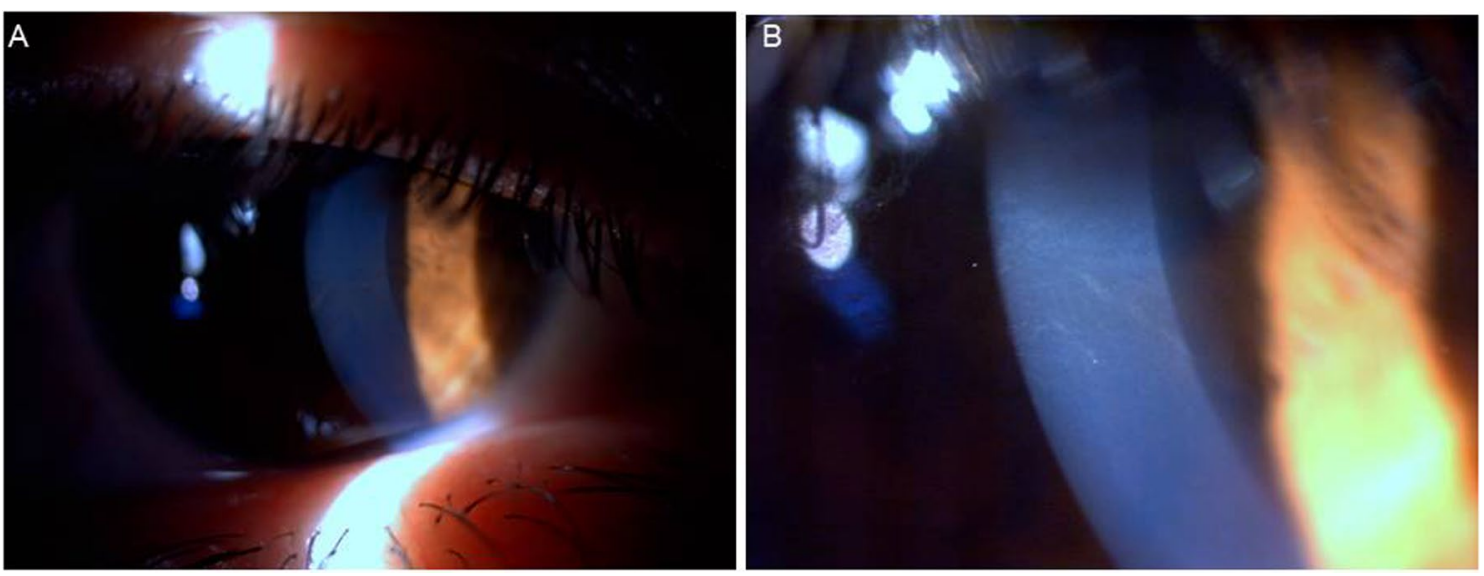

Fig. 5 A Biomicroscopic appearance of "cornea verticillata" in the right eye. B A higher magnification of the same patient demonstrating the whorl-like pattern of cornea verticillata 


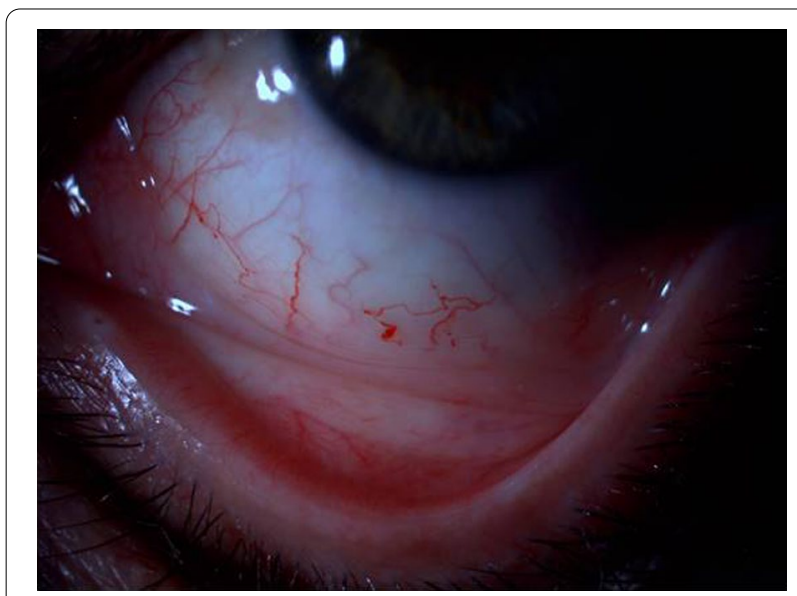

Fig. 6 Vascular tortuosity increase, telengiectasias, and aneurysmal changes of the conjunctival vessels of the left eye of a Fabry patient

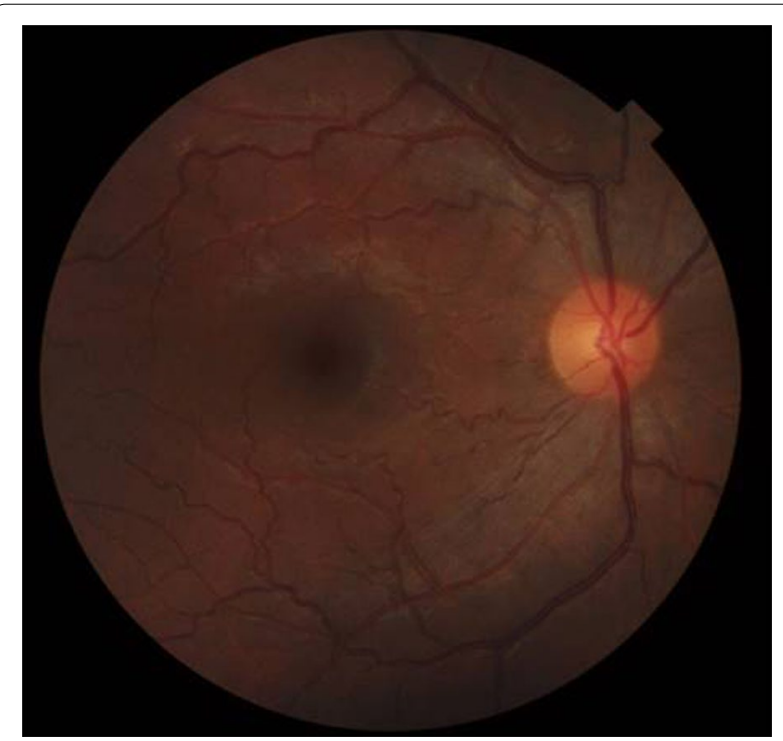

Fig. 7 Fundus examination of a Fabry patient showing increased retinal vascular tortuosity in the right eye

\section{The consensus statement on Fabry-specific ocular involvement}

- Ophthalmologic examination provides a unique and important opportunity to diagnose FD. Any patient with corneal haze, cornea verticillata, or Fabry cataract, especially in combination with retinal vascular tortuosity, conjunctival vascular telangiectasia, or lenticular opacities, should undergo a thorough review of symptoms and family history. Slit-lamp examination will be needed to reveal cornea verticillata [115].
- Ophthalmic findings in FD are more common in classical vs. late onset variant of disease [122]. Given that cornea verticillata is the most frequent eye finding in FD that can be easily detected by slit-lamp biomicroscopy with minimal inter- and intra-observer variability and independent of the influence of aging or environmental factors [115], potential use of cornea verticillata has been emphasized as a biomarker for FD $[114,115]$.

- Fabry cataract is usually regarded to be pathognomonic, whereas mannosidosis might cause the similar lens opacity and increased ocular vessel tortuosity has also been reported in healthy individuals as well as in fucosidosis [114, 115, 122-124].

- In addition, light microscopy in biopsy specimens from conjunctiva shows the accumulation of sphingolipids as PAS-positive Sudan-positive intra-lysosomal inclusions that are birefringent when viewed under polarized light [63].

- Hence, ophthalmologists often have the opportunity to identify patients early, before the disease is well advanced, emphasizing the likelihood of a heightened awareness of FD among ophthalmologists and optometrists to greatly reduce diagnostic delays and thus reduce the morbidity and mortality of this lifethreatening disease $[114,115]$.

\section{Dermatological involvement}

Dermatological abnormalities have been reported in $78 \%$ of males and $50 \%$ of females with the classic phenotype of FD [89]. Angiokeratoma is the most common dermatological abnormality occurring in $66 \%$ of males and in $36 \%$ of females, and is the most visible early clinical feature of classic FD [36]. They typically appear as clusters of small, pinkish, dark red, blue-black, non-blanching macules or papules $1-5 \mathrm{~mm}$ in size on the umbilicus, hands, knees, elbows, trunk and also sometimes on mucosal areas such as the mouth; spreading to the genitals during adolescence and increase in number and size with age (Fig. 8) $[36,89,125]$.

Angiokeratomas frequently appear in 5-15 years of age among males and in 8-25 years of age among females [126]. They typically are higher in number and frequently located in the genital region in males, while upper back and chest regions were more common locations in females [125].

Telangiectasia, the second-most common dermatological sign in FD, is commonly seen in sun-exposed areas such as "V" regions of the neck and face, while lip and oral mucosa are also likely locations (Fig. 9) [89, 127]. Sweating abnormalities (hypohidrosis in particular), lymphedema and hypotrichosis are other dermatological 

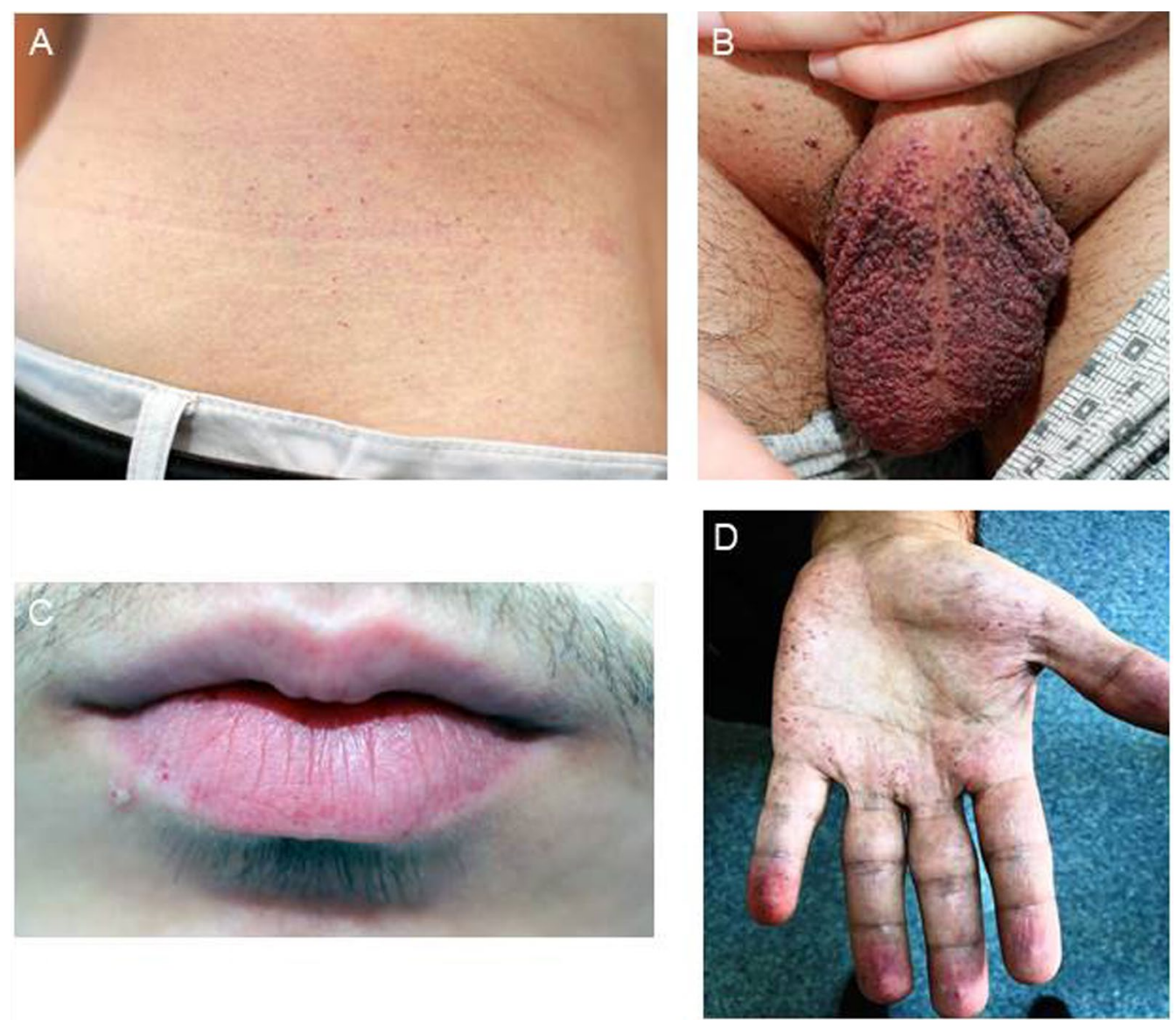

Fig. 8 Angiokeratoma A multiple small pink to dark-red spots in lateral trunk, B multiple 1-5 mm pink to dark-red or blue-black spots with hyperkeratotic surface in scrotum, $\mathbf{C}$ spots in the lower lip, $\mathbf{D}$ spots in the palm

signs of FD, while facial dysmorphism may also be evident among males (peri-orbital fullness, prominent supra-orbital ridges, large bitemporal width, bushy eyebrows, broad nasal base, fullness of the cheeks and a larger chin), albeit not a prominent sign in FD unlike to other several lysosomal storage disorders [128].

\section{The consensus statement on Fabry-specific dermatological involvement}

- Histologically, the skin lesions are small superficial angiomas caused by cumulative damage of the vascular endothelial cells of the skin with vessel dilatation in the dermis that increase in number and size with age and can occur singly or in groups $[89,128,129]$.

- Although skin biopsy may be a useful additional diagnostic test when carefully interpreted by an expert pathologist, the skin biopsies are often normal in heterozygous females and therefore not of great utility $[1,63,130]$.
- Angiokeratoma may be the first sign of FD as can be seen in at least half of overall cases and in at least two thirds of male patients [80].

- Although diffuse angiokeratomas (angiokeratoma corporis diffusum) are most commonly seen in FD, they are not FD-specific lesions and can also occur in other lysosomal storage disorders (i.e. mannosidosis, fucosidosis, sialidosis, b-galactosidase deficiency and Schindler disease) as well as in the absence of any metabolic disease or enzyme defect. Nonetheless, FD should be considered in a patient when angiokeratoma corporis diffusum is accompanied with other dermatological signs such as linear telangiectasia and sweating changes (i.e. hypohidrosis) [10, 36].

\section{Diagnosis of FD}

Despite presenting with peculiar signs and symptoms beginning in childhood, delays in diagnosis of FD are unfortunately very common with a mean diagnostic delay of $10-20$ years from symptom onset to definite diagnosis 

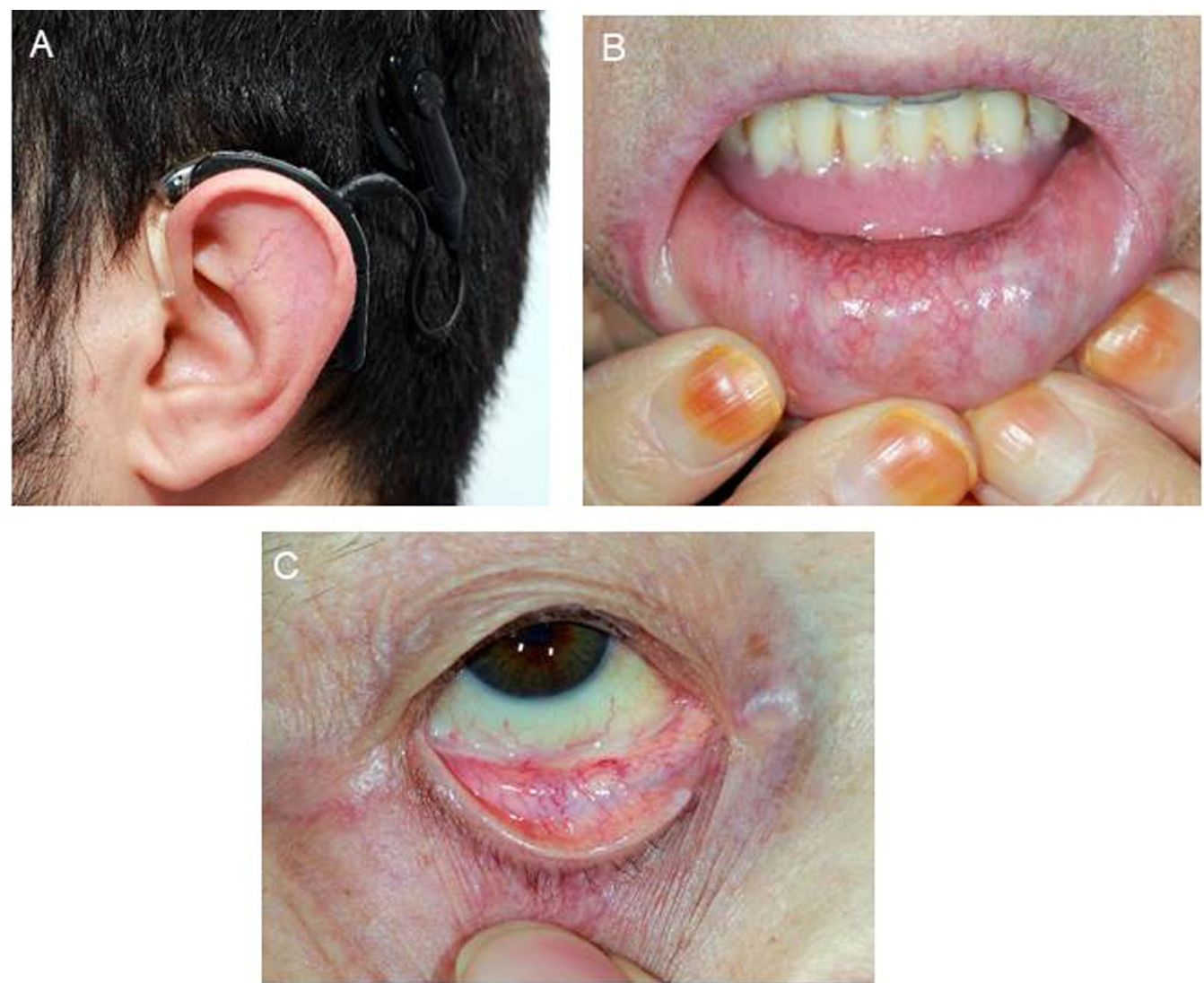

Fig. 9 Linear telangiectasia A in the auricle in a patient with sensorineural hearing loss, $\mathbf{B}$ in the lower lip mucosa, $\mathbf{C}$ in the conjunctiva

$[1,6-8,114]$. Alongside the fact that FD is generally poorly understood by physicians due to their lack of knowledge about this disorder, due to a highly heterogeneous nature of the disorder clinically with a wide variety of clinical manifestations between individual carriers of the same pathogenic variants and even within the same family, the timely diagnosis of FD remains a challenge [7, $114,131,132]$. On average, a patient with FD sees 10 specialists before the correct diagnosis is finally made and the disease usually is not diagnosed until patients are well into adulthood with average age of diagnosis of 29 years $[7,114,131,132]$.

The histopathology of kidney biopsy also provides significant evidence for FD especially when the enzyme level is uninformative, and the genetic testing reveals a VUS. The most characteristic finding on routine light microscopy of kidney biopsies is vacuolation of podocytes, of parietal epithelial cells of Bowman's capsule, and of Henle's loop and distal tubular cells. Mesangial widening, focal segmental glomerular sclerosis and global sclerosis, tubular atrophy, interstitial fibrosis and other nonspecific lesions are additionally seen, even at the early stages of Fabry nephropathy. On electron microscopy, the largest inclusions are seen in podocytes and in cells of the proximal and distal tubules, and Henle's loop. In these tubular segments, affected cells can be strikingly enlarged with giant inclusions measuring up $10 \mu \mathrm{m}$ in diameter [133].

\section{The consensus statement on diagnostic work-up for FD}

The diagnosis of FD is based on the disease's clinical manifestations and can be confirmed by the enzyme activity measurement, identification of glycosphingolipid accumulation, and genetic pathogenic variants studies [8]. The clinical suspicion of FD begins with identification of characteristic signs and symptoms such as neuropathic pain, angiokeratomas, ophthalmologic opacities (i.e. cornea verticillata and cataracts), anhidrosis or hypohidrosis, intolerance to exercise, heat or cold, gastrointestinal disturbances (i.e. bloating, diarrhea, abdominal pain), unexplained HCM (in men aged $>30$ years and women aged $>40$ years), ESRD at a young age or stroke in patients younger than 50 years with no cardio-vascular risk factors along with family history of FD and families with high prevalence of kidney disease, cardiomyopathy, or ischemic encephalopathy (Tables 2,3 , Fig. 10) $[1,4,7$, 10, 134-136]. 
Table 2 Clinical manifestations suggestive for Fabry diagnosis [1, 4, 7, 10, 134-136]

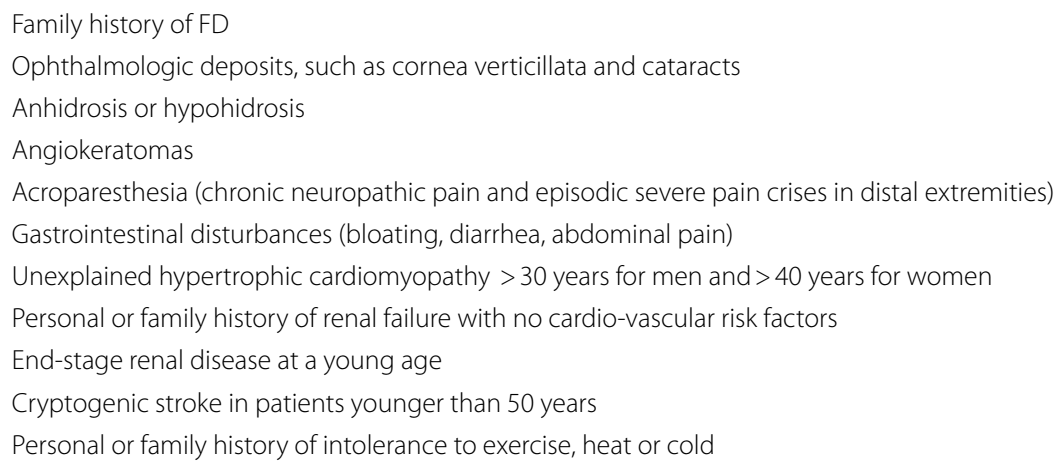

Table 3 Clinical manifestations suggestive for common misdiagnoses [1, 4, 7, 10, 134-136]

\begin{tabular}{|c|c|c|}
\hline Medical specialty & Misdiagnosis & Fabry symptom/sign \\
\hline \multirow[t]{4}{*}{ Neurology } & Multiple sclerosis & Stroke \\
\hline & Chronic small fiber neuropathy & Pain, tingling in hands and feet \\
\hline & Raynaud syndrome & Pain/ abnormal thermal sensitivity in extremities \\
\hline & Neurosis/malingering & Unexplained acute pain episodes \\
\hline \multirow[t]{4}{*}{ Rheumatology } & Rheumatoid or juvenile arthritis & $\begin{array}{l}\text { Joint pain, increased erythrocyte sedimentation } \\
\text { rate }\end{array}$ \\
\hline & Rheumatic fever & Pain accompanied by fever and increased ESR \\
\hline & Autoimmune disorder/lupus & Angiokeratomas \\
\hline & Growing pains & Unexplained pain in limbs \\
\hline Nephrology & (Glomerulo) nephritis & Renal insufficiency \\
\hline \multirow[t]{2}{*}{ Cardiology } & Carditis & Mitral murmur \\
\hline & Hypertrophic cardiomyopathy & Hypertrophic cardiomyopathy \\
\hline Dermatology & Petechiae & Angiokeratoma \\
\hline \multirow[t]{4}{*}{ Internal medicine/gastroenterology } & Vasculitis & Microvascular disease \\
\hline & Inflammatory bowel disease & Diarrhea, abdominal discomfort, N/N \\
\hline & Appendicitis & Severe abdominal pain in the right iliac fossa \\
\hline & Renal colic & Severe abdominal pain \\
\hline
\end{tabular}

ESR: Erythrocyte sedimentation rate; N/V: Nausea/vomiting

After diagnostic suspicion of FD is raised, the confirmation is made using laboratory testing. Detecting the deficiency in $\alpha$-Gal A activity in leukocytes stands as the gold standard for the diagnosis in males. Enzyme assay using dried blood spot (DBS) is generally used for screening and a positive result or a negative result in a highly suspected patient should always be confirmed by a second tier test such as $\alpha$-Gal A activity in leukocytes or genetic test. The enzyme levels in classical males is generally below $1 \%$ of normal whereas the levels may vary between 1 and $20 \%$ in late onset patients [7, 8, 39, 85]. Nonetheless, while $\alpha-G a l$ A activity testing alone is diagnostic for male patients; confirmation of the diseasecausing GLA pathogenic variants is needed to establish the disease phenotype, while pathogenic variants testing is also indicated to rule out benign polymorphisms, to perform preimplantation genetic diagnosis and to permit the testing of at-risk family members $[7,8,39,85]$.

In females, $\alpha$-Gal A activity can be normal due to random X-chromosomal inactivation, diagnosis in suspected cases should therefore be confirmed by demonstration of the presence of a disease-causing pathogenic variants in the $G L A$ gene via genetic analysis $[4,5,7,8,39,85]$.

Accordingly, given the role of molecular analysis of the GLA gene as an essential diagnostic or prognostic tool providing data on the exact kind of variants and related course of clinical manifestations, awareness of the treating physician about the different kinds of pathogenic variants and their clinical implications is highly important $[7,137]$. 


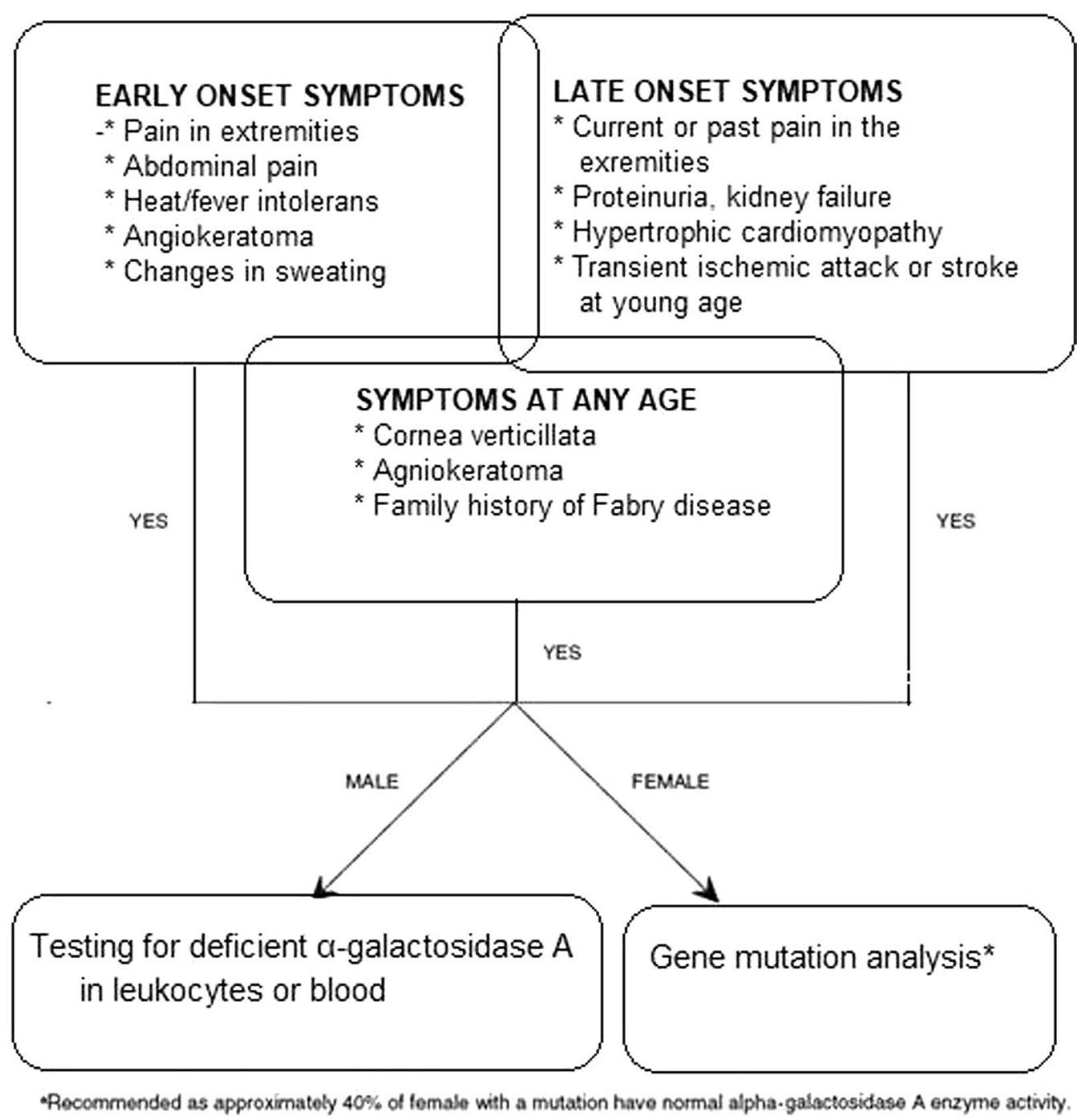

Fig. 10 Decision-making algorithm in diagnosis of Fabry disease. Adapted from Lidove et al. Clin Genet 2012: 81:571-577

Histopathologic examination of the kidney biopsy samples is of significant importance to provide evidence for FD when genetic testing reveals new variants (especially VUS).

FD is a multi-systemic disease with diverse range of possible alternative diagnoses related to several medical specialties, clinicians should therefore consider a diagnosis of FD when dealing with a wide range of symptoms that may be either specific to FD (both early- and late-onset symptoms) or non-specific, but which could fit within the phenotype of FD to address the diagnostic delay in FD and facilitate earlier therapy, leading to better outcomes [10].

Considering the significant number of applications to outpatient clinics and the increased risk of losing for follow-up in Turkey, enzyme analysis and genetic testing should be ordered simultaneously in male patients, whereas genetic testing should be the first option for diagnosing females as it is widely available in Turkey.

\section{Biomarkers for FD}

There is no ideal biomarker in FD, while microalbuminuria, proteinuria, and serum creatinine are the usual biomarkers for renal monitoring. Nonetheless, some rarely used biomarkers such as cystatin $C$, beta 2 -microglobulin $(\beta 2 \mathrm{M})$ and neutrophil gelatinase-associated lipocalin/lipocalin-2 creatinine have also been investigated in FD patients [138]. Hence, authors noted that along with serum creatinine, measurement of $\beta 2 \mathrm{M}$ or cystatin $\mathrm{C}$ should be considered for renal evaluation 
of FD patients [138]. Similarly, the utility of the aminoterminal fragment of the brain natriuretic propeptide (NT-proBNP) has subsequently been confirmed as a diagnostic and prognostic predictor of heart disease $[139,140]$.

Plasma Lyso-Gb3 levels, deacylated form of Gb3 rather than urine or plasma Gb3levels are considered more sensitive markers. Although in some studies correlation of lyso-Gb3 levels with some cardiac and neurological manifestations other studies have not found such associations $[6,141]$. Lyso-Gb3 contributes to the pathology of disease $[1,42,142-144]$. Nonetheless, the utility of LysoGb3 is still controversial, due to concerns that LysoGb3 levels may not be strongly associated with disease phenotype [13]. Other potential biomarkers in FD include plasma 3-nitrotyrosine, podocyturia and urinary excretion of CD80 [145, 146], while sphingosine-1-phosphate (S1P) was recently identified as a biologically active growthpromoting factor involved in cardiovascular remodeling in both males and females with FD plasma levels of which show a strong correlation with LVM index, and increased common carotid artery intima-media thickness [147]. There is a need for studies to help identify new therapeutic targets and reliable biomarkers for diagnosis and prognosis of FD as well as to assess treatment response $[1,139]$.

\section{Clinical suspicion, over suspicion, screening and genetic counselling}

Screening individuals with a family history of FD or newborn screening programs are the only practical ways of identifying patients before the development of symptoms, while screening of patients in high risk groups who may be exhibiting late-onset symptoms of FD is also considered important in optimizing the management of disease in these patients [1].

Once the diagnosis has been confirmed, the opinion of a pediatric metabolic physician, pediatric or medical geneticist should be sought and family screening carried out, and the Pedigree analysis and effective screening of the family of a newly diagnosed patient is likely to result in identification of several previously unrecognized affected family members, including young relatives at a relatively early stage of their disease $[148,149]$.

The high-risk populations include individuals with LVH, ESRD and crytogenic stroke and/or small-fiber neuropathy [36] as reported to be associated with $1.14 \%$, $0.3 \%$ and $1.6 \%$ of FD prevalence, respectively in a systematic review of previous large studies [150]. In fact, screening studies for FD may reveal individuals with genetic variants of yet unknown significance and may inadvertently indicate falsely higher prevalence due to benign polymorphisms (e.g., D313Y) [23, 39, 150].

\section{The consensus statement on interpretation of pathogenic variants}

Nowadays, FD diagnosis rate is increasing via pedigree analysis or family screening after diagnosis of another family member, and use of DNA sequencing technologies (either Sanger sequencing or Next Generation Sequencing) rather than enzymatic screening is becoming more widespread for screening of at-risk groups. However, while is a useful innovative technology, it may lead to the identification of genetic variants of unknown significance (VUS), which are often not associated with the characteristic features of FD $[1,4,8]$. This seems notable given the challenges in interpretation of genetic GLA pathogenic variants to predict the pathogenicity for a GLA VUS, which necessitates further clinical, biochemical, or histopathological evidence of FD in individuals with a GLA VUS to determine the pathogenic nature of the pathogenic variants, before initiation of therapy $[1,4,39,151]$. In this regard, de novo pathogenic variants which were not described before require further clinical investigation including brain and cardiac MRI, an electron microscopy analysis of the biopsy of the affected organ to look for Gb3 deposits and a thorough family testing to find and investigate males with low $\alpha$-Gal A activity and the same pathogenic variants that would support variants being pathogenic [7, 12, 39, 136, 152, 153]. In addition, most of the pathogenic GLA pathogenic variants are private, occurring in a single or few families; intra-familial phenotypic variability has been observed, complicating the study of genotype-phenotype correlations (Fig. 11) [1, 39].

Accordingly, while the identification of pathogenic variants within the GLA gene is important to the diagnosis of FD, other questions have emerged regarding how to elucidate VUS and how to explore potential genotype-phenotype relationships to perform correct risk stratification $[8,13]$ While the "gold standard" to clarify if a novel pathogenic variant is likely pathogenic or likely benign includes in vitro GLA pathogenic variants expression assays, this is only available at specialized research laboratories [148]. There are also controversial variants [7], like the p.D313Y and some intronic variants, described early in literature as pathogenic by some authors [154] and later as benign by others [155]. Therefore, the advice of an expert in pediatric metabolic diseases, as well as pediatric or medical genetics should be sought for interpretation of the pathogenicity of any VUS [39], while more importantly, the treating physician should always rely on the patients' clinical manifestations 


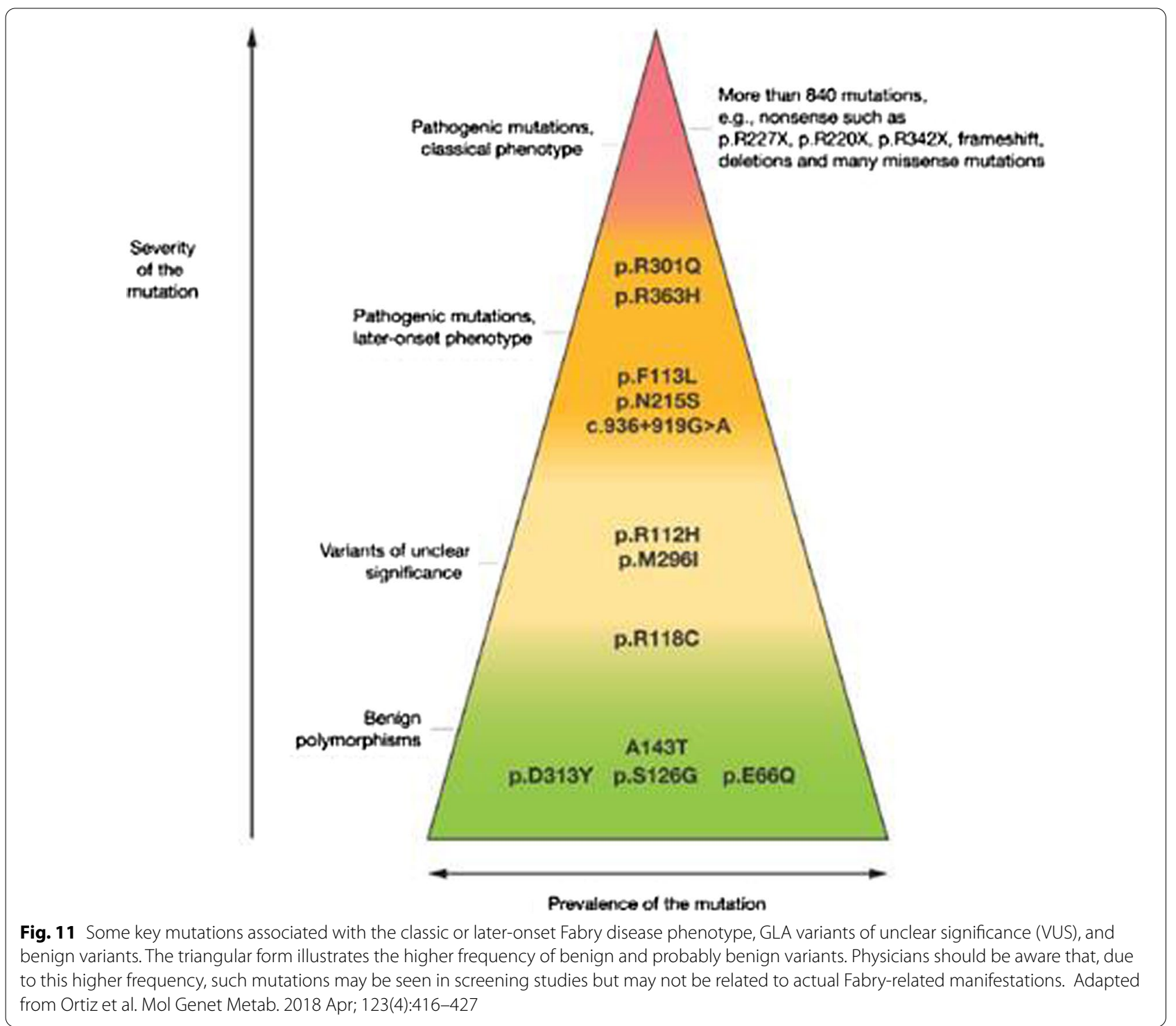

and examination, besides the genotype, when deciding whether to begin treatment $[7,156]$.

There is increasing awareness of FD among primary care physicians and different specialists, and systematic screening among high-risk populations and newborns has become more frequent [13]. Notably, a new emergence challenge in the field of Fabry diagnosis is over suspicion due to increased awareness of a rare disease that has become treatable with ERT and thus the idea of having a specific therapy to offer to a potential patient made the physician to put FD as one of the first in the list of diseases for differential diagnosis when only one sign of symptom is present in his or her patient [12]. This has been associated with remarkable increase in the number of samples received by reference labs specialized in Fabry diagnosis and thus decline in the proportion of positive cases along with increased detection of pathogenic variants with unknown clinical relevance [13, 136, 157]. This emphasizes the need for a more complete clinical picture, medical history, and family history in order to decide, especially in females, which samples should be tested [12].

Accordingly, screening based on solid criteria for the high clinical suspicion and correct interpretation of pathogenicity of pathogenic variants (i.e., awareness of polymorphisms like p.D313Y p.E66Q, and probably p.R118C with high residual activity) are crucial to establish final diagnosis [12, 39].

Based on the reports about the pathogenic variant spectrum of the patients from Turkey, consistent with the 
rest of the world, recurrent pathogenic variants are rare $[14,158]$.

It is a fact that enzyme assay from dried blood spots could reveal false positive or negative results unless confirmed by a second-tier test. The novel variants in the GLA gene could be misinterpreted as "pathogenic" due to various reasons. Based on these facts it is highly possible that some cases have erroneously been put on therapy although they do not have Fabry Disease [7].

\section{Treatment of FD}

FD is characterized by progressive, multi-organ pathology manifesting as a range of clinical phenotypes affecting both genders in terms of poor QoL, morbidity and shortened life expectancy $[1,36]$. Currently, ERT and chaperone therapy are the two therapeutic modalities available clinically for the treatment of FD, while other alternatives such as substrate reduction therapy, mRNA based therapy, and gene therapy are in development (Fig. 12) [42, 159].
ERT, the first approved disease-specific therapeutic option for patients with FD, remains the mainstay of treatment for most patients as associated with improved patient QoL and stabilized kidney function worsening [159]. However, given the unmet clinical needs via ERT, investigational therapies are directed at either replacing or generating deficient enzyme, or blocking the accumulation of substrate [159]. Strategies targeting enzyme delivery or production include modification of the enzyme to increase the duration of therapeutic plasma concentrations, mRNA administration, and gene therapy, while non-enzyme-replacement strategies including substrate reduction therapy are currently in clinical trials and aims to reduce GB-3 production by inhibiting glucosylceramide synthase [159]. Chaperone therapy, recently approved (although not available in Turkey yet), stabilizes the endogenous enzyme in patients with amenable pathogenic variants to increase enzyme activity (Fig. 12) [159].

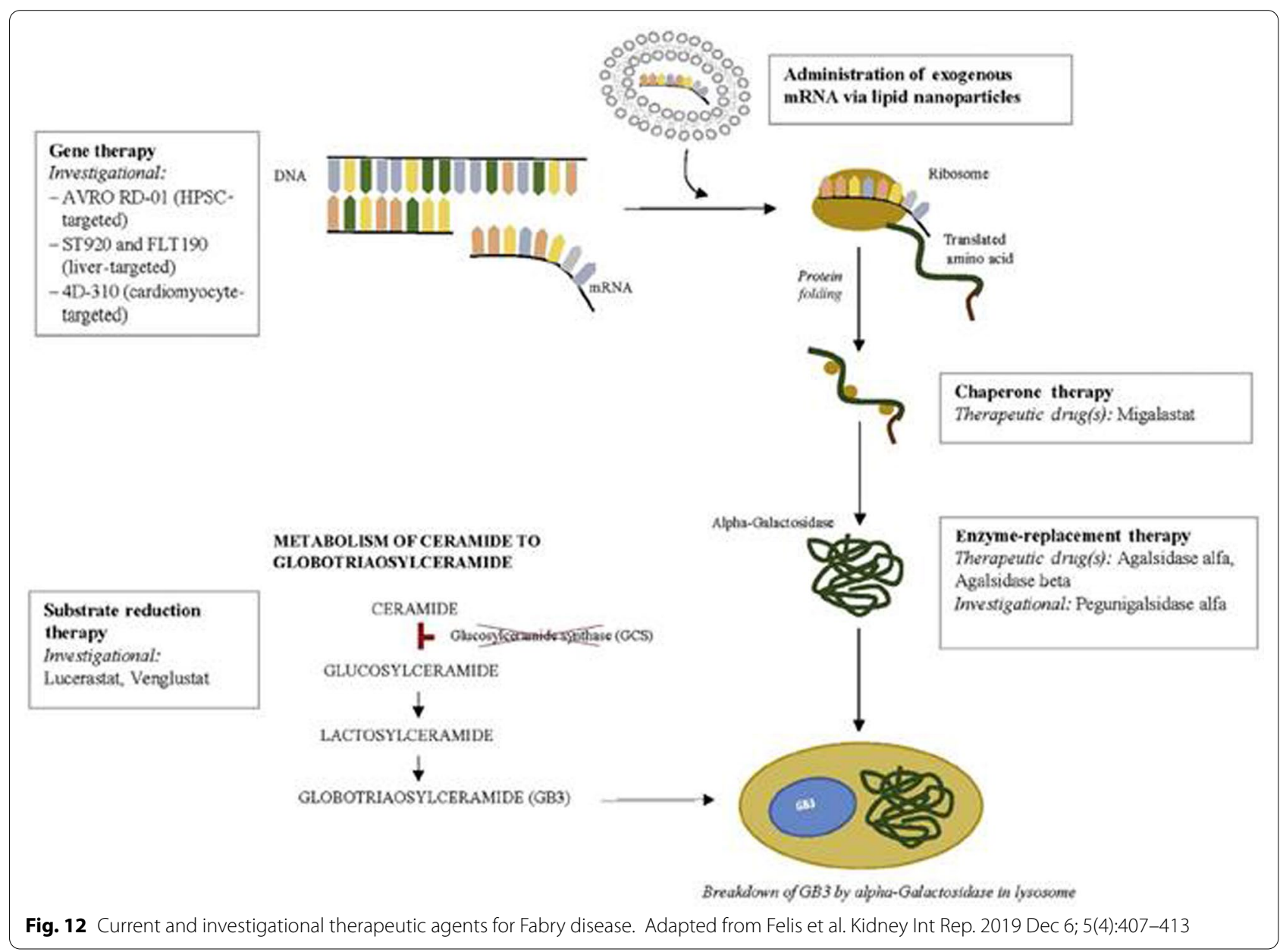




\section{Enzyme replacement therapy}

For ERT, there are two available pharmaceutical preparations of recombinant human $\alpha$-Gal A including agalsidase alfa (Replagal ${ }^{\circledR}$ by Shire Human Genetic Therapies, Lexington, MA) and agalsidase beta (Fabrazyme $^{\circledR}$ by Sanofi Genzyme, Cambridge, MA) produced in a lineage of human fibroblasts and in Chinese Hamster Ovary $(\mathrm{CHO})$ cells, respectively. Both preparations have similar glycosylation patterns, specific activities, and enzyme kinetics [160] and both have been shown to be clinically efficacious $[9,32]$. Both preparations are administered intravenously every other week and indicated for long-term treatment [36, 42]. Agalsidase alfa is given with a dose of $0.2 \mathrm{mg} / \mathrm{kg}$ and agalsidase beta is given as $1 \mathrm{mg} / \mathrm{kg}$ both with biweekly infusions $[17,37$, 161, 162].

Clinical trials, observational studies and registry data have provided many evidences for safety and efficacy of ERT in improving symptoms of pain, gastrointestinal disturbances, hypohidrosis, left ventricular mass index, GFR and QoL $[98,163]$. ERT is considered able to stabilize the pathogenic processes, prevent progression of the disease, improve disease outcome, and increase the QoL among FD patients $[8,164]$. For the renal phenotype, ERT seems to stabilize kidney function worsening in these patients and at least slow their decline in renal GFR [58]. For the cardiac phenotype, ERT is able to stabilize or improve surrogate parameters like cardiac size among individuals with cardiomyopathy [165]. Data published in adult male patients with FD demonstrates that the efficacy of ERT with consistent, dose-dependent reductions in Gb3 accumulation, a reduced decline in eGFR, and improvements in cardiac outcomes along with gastrointestinal, pain and QoL outcomes or stabilization of a lifetime progressive debilitating disease [37].

Nonetheless, ERT has some limitations due to a restricted volume of distribution, requirement for intravenous access, and stimulation of the production of anti-drug antibodies as well as limited efficacy including continued progression of cardiac fibrosis and progression of white matter disease on ERT $[159,166]$. Pegunigalsidase alpha is a novel pegylated form of $\alpha$-GAL produced in a PlantCell Ex system and an investigational ERT with preclinical data supporting longer circulatory half-life, increased cardiac and renal uptake and decreased hepatic uptake than currently available ERT preparations [167, 168]. The data from an open-label, 3-month pharmacokinetics study followed by 9 months of follow-up also confirmed a longer half-life (average $80 \mathrm{~h}$ ) when compared to half-life of $2 \mathrm{~h}$ for existing therapies along with a favorable tolerability profile and a 50\% reduction in GB-3 in majority of patients, particularly in those with classic pathogenic variants [169].
In Turkey, generally the criteria for initiating ERT for patients is parallel to the international recommendations stating that symptomatic patients as well as asymptomatic boys with classical Fabry pathogenic variants around age 8-10 years should be considered for treatment $[39,170]$.

\section{Chaperone therapy}

Some missense mutations within the GLA gene often result in an unstable and misfolded protein, leading to reduced intracellular AGAL activities. Misfolded proteins will not pass the protein quality-control mechanism within the endoplasmic reticulum (ER), resulting in premature degradation before reaching the lysosomes. To restore folding and stability of the protein, pharmacological chaperones can be used, binding reversibly to the active center of the protein [171]. Migalastat (Galafold; Amicus Therapeutics, Cranbury, NJ), a pharmacological chaperone, is an orally bioavailable iminosugar that increases available enzyme activity in patients with pathogenic variants s amenable to the therapy $[159,166]$. It has been associated with improved protein folding and promoted trafficking of the protein to the lysosome by binding to the defective $\alpha-G A L$ in the endoplasmic reticulum [172]. Two phase III studies were conducted with migalastat conducted. The FACETS study is a placebo-controlled study including treatment-naïve patients $(\mathrm{N}=50 ; 22$ placebo vs. 28 migalastat). Although there was no significant difference between the number of responders $(\geq 50 \%$ reduction in the number of GL-3 inclusions per kidney interstitial capillary) in the placebo and migalastat groups, six months of migalastat was associated with a significantly greater reduction in the mean $( \pm \mathrm{SE})$ number of GL-3 inclusions per kidney interstitial capillary than was placebo. In patients who received migalastat for up to 24 months, a significant decrease in the left-ventricular-mass index was observed [173]. In the ATTRACT study, migalastat is compared to enzyme replacement (agalsidase-beta, agalsidase-alfa) in 57 patients (36 migalastat vs. 21 ERT males and females). Renal function was stable for 18-month treatment period with migalastat, a signifcant reduction of the left ventricular mass index was observed, and plasma lyso-Gb3, as a marker of disease burden, remained low and stable when switching from ERT to migalastat [174].

Recently, a single-center observational study on seven male Fabry patients (18-66 years) who switched from ERT to migalastat treatment revealed that cardiac, renal and neurologic functions, and FD-related symptoms and questionnaires were stable between baseline and the switch, and remained unchanged with migalastat. A significant improvement was observed in left ventricular mass index from baseline (diagnosis of FD) to T2 (1 year 
Table 4 Adjunctive support for the management of Fabry disease [39, 180]

\begin{tabular}{|c|c|}
\hline Organ/system involvement & Adjunctive/symptomatic therapy and preventative measures \\
\hline \multicolumn{2}{|l|}{ Renal } \\
\hline \multirow[t]{4}{*}{ Proteinuria and reno-protection } & ACE inhibitor or ARB \\
\hline & Dietary salt restriction \\
\hline & Statin therapy \\
\hline & Vitamin D replacement therapy if needed \\
\hline Renal failure & Dialysis or kidney transplantation (donor screened negative for FD) \\
\hline \multicolumn{2}{|l|}{ Cardiac } \\
\hline Hypertension & $\begin{array}{l}\text { ACEl or ARB (beta blockers should be used with caution and amiodarone avoided in patients receiv- } \\
\text { ing ERTa) }\end{array}$ \\
\hline $\begin{array}{l}\text { Symptomatic bradycardia/chronotropic } \\
\text { incompetence or significant AV conduction } \\
\text { impairment }\end{array}$ & Permanent cardiac pacing \\
\hline Atrial fibrillation & Lifetime anticoagulation with maintenance of sinus rhythm \\
\hline Malignant arrhythmias & Implantable cardioverter-defibrillator \\
\hline \multicolumn{2}{|l|}{ Neurologic } \\
\hline \multirow[t]{2}{*}{ Stroke prophylaxis } & $\begin{array}{l}\text { Antithrombotic agents (aspirin or clopidogrel) as secondary prevention; no data available regarding } \\
\text { primary prevention }\end{array}$ \\
\hline & $\begin{array}{l}\text { Anticoagulants (warfarin or the new anticoagulant drugs in absence of kidney failure), when needed, } \\
\text { e.g., patients with atrial fibrillation }\end{array}$ \\
\hline Neuropathic pain management & $\begin{array}{l}\text { First-line agents include anticonvulsants (e.g., carbamazepine, gabapentin, pregabalin); other drugs } \\
\text { can be considered according to current international recommendations for neuropathic pain }\end{array}$ \\
\hline Pain crises & Opioid agonists (care needed to avoid worsening Gl disturbances) \\
\hline Avoiding pain triggers & $\begin{array}{l}\text { Lifestyle modifications (e.g., avoid temperature extremes, maintain proper hydration, use air condi- } \\
\text { tioning, cooling vests, facial mist/spray) }\end{array}$ \\
\hline \multicolumn{2}{|l|}{ Psychiatric } \\
\hline Depression, anxiety & Psychiatric referral, pain center referral, serotonin reuptake inhibitors \\
\hline \multicolumn{2}{|l|}{ Gastrointestinal } \\
\hline Delayed gastric emptying & Metoclopramide \\
\hline Dyspepsia & $\mathrm{H}-2$ blockers \\
\hline Dysmotility and diarrhea & Dietary changes (increased fiber intake, more frequent and smaller meals) and pharmacotherapy \\
\hline \multicolumn{2}{|l|}{ Pulmonary } \\
\hline Airway obstruction & Bronchodilators \\
\hline \multicolumn{2}{|l|}{ Ophthalmological } \\
\hline \multirow[t]{2}{*}{ Difficulty in driving at night } & Polarized glasses \\
\hline & Artificial tears ointment \\
\hline \multicolumn{2}{|l|}{ ENT } \\
\hline Hearing loss & Hearing aids, cochlear implants \\
\hline Vertigo-related nausea & Trimethobenzamide, prochlorperazine \\
\hline \multicolumn{2}{|l|}{ Dermatological } \\
\hline Angiokeratomas & Laser/cosmetic treatment (not proven effective) \\
\hline Lymphedema & Compression stockings \\
\hline
\end{tabular}

ACE: Angiotensin converting enzyme; ARB: Angiotensin receptor blocker; AV: Atrioventricular; ENT: Ear-nose-throat; ERT: Enzyme replacement therapy; FD: Fabry disease

of therapy with migalastat) $(p=0.016)$, with a significative difference between the treatments $(p=0.028)$, and in median proteinuria from T2 versus T1 $(p=0.048)$ [175].

There are more than 1000 mutations in the GLA gene known to be associated with Fabry disease; an estimated $35-50 \%$ of patients with Fabry disease have mutations that are amenable to migalastat therapy. Based on a HEK
293 cell based assay, migalastat-amenable mutations are defined as those in GLA that translate to mutant forms of $\alpha$-galactosidase $A$ and display $a \geq 1.2$-fold increase in $\alpha$-galactosidase A activity over baseline and an absolute increase of $\geq 3 \%$ over wild-type $\alpha$-galactosidase A activity, in the presence of $10 \mu \mathrm{mol} / \mathrm{L}$ migalastat [176]. 


\section{Substrate inhibition therapy}

Substrate reduction therapies such as lucerastat (Idorsia Pharmaceutical Ltd, Allschwil, Switzerland) and venglustat (Sanofi Genzyme, Cambridge, MA) function as a glucosylceramide synthase inhibitor preventing accumulation of GB-3 by limiting the amount of ceramide that is converted to glycosphingolipid [177]. Preliminary data from clinical trials evaluating the effect of Venglustat in treatment-naïve Fabry patients suggest a slow but gradual clearance of Gb3 from superficial skin capillary endothelium and a gradual decrease of plasma lysoGb3 in most included patients over the course of 3 years of treatment [178].

\section{Gene therapy}

Gene therapies include gene editing with the ex vivo approach where hematopoietic stem cells harvested from the patient are infused back into the patient after gene editing and the in vivo approach where a vector with gene editing is infused directly into the patient, and then cells within the patient, such as liver cells, directly undergo gene editing to express the missing protein [160].

Administration of $\alpha$-GAL mRNA to stimulate production of $\alpha-G A L$ without the need for either myeloablative therapy or administration of viral vectors for gene transduction is another therapeutic approach that is currently under testing [160]. Nonetheless, whether or not the current gene therapy approaches will achieve stable viral copy numbers and sufficient $\alpha$-GAL A activity compared to currently available or developing long-lived ERT preparations remains to be clarified for gene therapy approaches to be adopted as therapeutic interventions for FD $[159,179]$.

\section{Adjunctive therapies}

Treatment with ERT should be combined with supportive interventions, if indicated, to clinically manage the renal, cardiac, neurological, and other complications of Fabry disease-induced chronic tissue injury [39].

Adjunctive treatment includes analgesic drugs, renocardio-protection [angiotensin converting enzyme (ACE) inhibitors and angiotensin receptors blockers (ARBs), statin therapy, adherence to a low-sodium diet, antiarrhythmic and anticoagulant agents and vitamin D repletion as needed] and lifestyle modifications (e.g., avoiding extremes of temperature), whereas dialysis or renal transplantation are available for patients experiencing ESRD (Table 4) $[1,23,39,180]$.

\section{The consensus statements on management of FD}

- The general therapeutic goal for optimizing patient management in FD should be to optimize both dis- ease-specific and nonspecific adjunctive treatments to prevent or minimize effects of organ damage (e.g. kidney dysfunction) and prevent clinical events (e.g. stroke) as well as reduce symptoms, such as neuropathic pain [36].

- The management of FD should be carried out by an experienced multidisciplinary team based on an individualized approach to patient care consistent with the natural history of the specific disease phenotype and should involve early ERT initiation after comprehensive evaluation of disease involvement, routine monitoring for evidence of organ involvement in late onset asymptomatic patients and response to therapy in treated patients to regularly re-evaluate and appraise the therapeutic goals and use of adjuvant treatments to assist in the management of organ-specific complications [36, 39].

- There is growing evidence that early initiation of ERT optimizes treatment benefits, and can potentially prevent or delay progression to permanent organ damage [36]. Accordingly, the present expert panel agreed that ERT should be initiated as soon as possible on presentation of early clinical signs related to kidney, heart, or brain involvement in order to achieve the best efficacy and to avoid irreversible pathological changes given that the earlier treatment with ERT is begun, the greater the potential for benefit $[1,8,85,181]$.

- For male patients with a classic Fabry pathogenic variants, ERT should be initiated promptly when there are clinical manifestations, but should be considered for males older than 10 years of age even in the absence of clinical signs or symptoms of organ involvement. In addition, female patients with classical pathogenic variants or patients with later onset Fabry pathogenic variants should be treated as soon as possible ERT if they present with symptoms suggesting major organ (kidney, heart, or brain) involvement or laboratory, histological, or imaging evidence of injury to the major organs.

- Tissue-based assessment of FD pathology may assist the decision to initiate ERT and may occasionally be helpful in assessing disease progression and response to treatment during follow-up. The treatment should not be withheld from patients with severe renal insufficiency or with renal transplantation, from those on dialysis, or those with cognitive decline [8, 39].

- Given the rising number of pregnant women with FD, it should also be noted that the agalsidase alfa [182] and agalsidase beta [183] treatments was reported to be safe and well tolerated during pregnancy and lactation, with no adverse events reported in mothers and children in the case series studies. 
Nevertheless, further studies in pregnant FD patients are needed to better understand the benefits and risks of therapy and to justify the universal use of ERT among all pregnant women with symptomatic FD $[182,183]$.

- Strategies to optimize the management FD patients involves timely use of ERT along with appropriate non-specific adjunctive therapies through an individualized optimal treatment strategy suiting patient's clinical signs and symptoms and improving QoL which is often impaired even in early-stage disease because of neuropathic pain, whereas a need for further investigation is obvious that would address the potential invasive or non-invasive markers of disease progression as well as the impact of seroconversion and IgG antibody production on treatment response among FD patients [36].

- While the advent of potential alternative therapeutic agents hold potential promise for FD patients, their combined use should also be investigated in future studies in terms of potential to enable better outcomes and treatment of organ-specific sequelae of FD should be continued via standard-of-care adjunctive therapies [159].

- Being the only approved treatment option in Turkey, enzyme replacement therapy stays as the first choice for the etiology targeted treatment in indicated patients.

\section{Multidisciplinary approach for evaluation and management}

Given its multi-systemic nature, setting up a medical care plan for FD should ensure interdisciplinary communication across the specialties managing different organ complications [4,36]. Awareness in medical community about FD should be one of the main activities from reference professionals in the field of lysosomal diseases [12]. Therefore, cardiologists, neurologists, dermatologists, nephrologists and ophthalmologists should all be aware of the possibility of FD, depending on the patient's clinical presentation [4]. Moreover, the effective management of FD requires a multidisciplinary approach and a follow-up program that involves comprehensive teamwork, which should ideally be supervised by physician experienced in the management of patients with FD, with input from sub-specialists who also have FD experience, as part of a multidisciplinary clinical team that includes pediatric metabolic physicians, pediatricians, ophthalmologists, nephrologists, cardiologists, neurologists, gastroenterologists, dermatologists, genetic counselors, pediatric or medical geneticists, psychologists, trained pathologists, and professional nurses [8, 38, 162].

\section{Conclusion}

This consensus statement indicated the clinical heterogeneity of FD as well as a large number of pathogenic variants in the GLA gene, emphasizing a need for an individualized approach to patient care in accordance with genotype, gender, family history, phenotype, and specific clinical symptom severity of a given patient. The experts reached consensus on the critical role of a high index of suspicion in symptomatic patients and screening of certain at risk groups to reveal timely and accurate diagnosis of FD along with consideration of various causes of small-fiber neuropathy, cryptogenic young stroke and sarcomeric HCM in the differential diagnosis. The expert panel emphasized the need for increased awareness of the treating physician about the different kinds of pathogenic variants $s$ and their clinical implications as well as necessity of further clinical, biochemical, or histopathological evidence of FD to determine the pathogenicity of VUS variants in GLA gene. The expert panel agreed on the diagnostic and prognostic role of histological changes on renal biopsy as become evident before clinical and laboratory indicators of disease, the role of MRI in differential diagnosis of Fabry-specific cardiac and cerebrovascular involvement and higher specificity of ocular manifestations with higher opportunity of ophthalmologists to identify FD patients at early period. The expert panel emphasized a need for a coordinated, multidisciplinary care approach in the management of FD with early start of treatment, tailoring the treatment to the needs of individual patients and regular assessment of disease progression in all patients to obtain the therapeutic goals for improving QoL and reducing progression of the disease or to stabilize end organ structure and function. The experts emphasized the crucial role of timely recognition of FD with minimal delay from symptom onset to definite diagnosis in better management of FD patients, given the likelihood of changing the disease's natural history, improving the patients' QoL and the prognosis via ERT once a diagnosis is made. In this regard, this consensus document is expected to increase awareness among physicians about unique characteristics of FD to assist clinicians in recognizing FD with a well-established clinical suspicion consistent with pathogenic variants and gender-based heterogeneous clinical manifestations of FD and in translating this information into their clinical practice for best practice in the management of patients with FD.

\footnotetext{
Abbreviations

a-Gal A: a-Galactosidase A; $32 \mathrm{M}$ : Beta 2-microglobulin; CKD: Chronic kidney disease; CWML: Cerebral white matter lesions; ERT: Enzyme replacement therapy; ESRD: End-stage renal disease; FD: Fabry disease; Gb3: Globotriaosylceramide; GFR: Glomerular filtration rate; Gl: Gastrointestinal; HCM: Hypertrophic cardiomyopathy; IBS: Irritable bowel syndrome; LVH: Left ventricular
} 
hypertrophy; MRI: Magnetic resonance imaging; MRS: MR spectroscopy; NT-proBNP: Brain natriuretic propeptide; PET: Positron emission tomography; QoL: Quality of life; TCD: Trans-cranial Doppler; TIA: Transient ischemic attack; VUS: Variants of unknown significance.

\section{Acknowledgements}

We thank to Cagla Ayhan, MD and Prof. Sule Oktay, MD, PhD. from KAPPA Consultancy Training Research Ltd, Istanbul who provided editorial support funded by Sanofi Genzyme Turkey.

\section{Authors' contributions}

The authors equally contributed to the literature review and the writing of the manuscript. All authors read and approved the final manuscript.

\section{Funding}

The present study of the Fabry experts was supported by Sanofi Genzyme Turkey which played a role in organization of expert panel meetings including invitation of participants and compensation for the time and transport expenses of the experts. Sanofi Genzyme Turkey had no role in study design, data collection and analysis, decision to publish, or preparation of the manuscript.

\section{Availability of data and materials}

All data are available through cited literature.

\section{Declarations}

Ethics approval and consent to participate

Not applicable.

\section{Consent for publication}

Not applicable.

\section{Competing interests}

The authors declare that they have no competing interests.

\section{Author details}

'Department of Pediatrics, Division of Pediatric Metabolism and Division of Pediatric Genetics, Gazi University Faculty of Medicine, 06560 Ankara, Turkey. ${ }^{2}$ Department of Dermatology, Akdeniz University Faculty of Medicine, Antalya, Turkey. ${ }^{3}$ Clinic of Nephrology, Kartal Dr. Lutfu Kirdar Training and Research Hospital, Istanbul, Turkey. ${ }^{4}$ Department of Pediatrics, Division of Pediatric Rheumatology, Istanbul University Cerrahpasa Faculty of Medicine, Istanbul, Turkey. ${ }^{5}$ Department of Ophthalmology, Ege University Faculty of Medicine, Izmir, Turkey. ${ }^{6}$ Department of Medical Genetics, Ege University Faculty of Medicine, Izmir, Turkey. ${ }^{7}$ Department of Pathology, Baskent University Faculty of Medicine, Ankara, Turkey. ${ }^{8}$ Department of Neurology, Hacettepe University Faculty of Medicine, Ankara, Turkey. ${ }^{9}$ University of Health Sciences Department of Cardiology, Ankara City Hospital, Ankara, Turkey.

Received: 24 August 2021 Accepted: 6 February 2022 Published online: 02 March 2022

\section{References}

1. Germain DP. Fabry disease. Orphanet J Rare Dis. 2010;5:30.

2. Elliott PM, Germain DP, Hilz MJ, Spada M, Wanner C, Falissard B. Why systematic literature reviews in Fabry disease should include all published evidence. Eur J Med Genet. 2019;62:103702.

3. Concolino D, Degennaro E, Parini R. Fabry Delphi working group; Fabry Delphi working group. Delphi consensus on the current clinical and therapeutic knowledge on Anderson-Fabry disease. Eur J Intern Med. 2014;25:751-6.

4. Hagège $A$, Réant $P$, Habib G, Damy T, Barone-Rochette $G$, Soulat $G$, et al. Fabry disease in cardiology practice: literature review and expert point of view. Arch Cardiovasc Dis. 2019;112:278-87.

5. Echevarria L, Benistan K, Toussaint A, Dubourg O, Hagege AA, Eladari D, et al. X-chromosome inactivation in female patients with Fabry disease. Clin Genet. 2016;89:44-54.
6. Calderón Sandubete EJ, de la Blanca EBP, Alonso-Ortiz Del Río C, Santamaría Olmo R, López Mendoza M, Barcos Martínez M, et al. Spanish multidisciplinary clinical practice guidelines for Anderson-Fabry Disease in Adults. I. Method and recommendations. Rev Clin Esp. 2019;219:200-7.

7. Curiati MA, Aranda CS, Kyosen SO, Varela P. The challenge of diagnosis and indication for treatment in Fabry disease. J Inborn Errors Metab Screen. 2017;5:1-7.

8. Hsu TR, Niu DM. Fabry disease: review and experience during newborn screening. Trends Cardiovasc Med. 2018;28:274-81.

9. Schiffmann R, Kopp JB, Austin HA III, Sabnis S, Moore DF, Weibel T, et al. Enzyme replacement therapy in Fabry disease: a randomized controlled trial. JAMA. 2001;285:2743-9.

10. Lidove O, Kaminsky P, Hachulla E, Leguy-Seguin V, Lavigne C, Marie I, et al. Fabry disease "the new great imposter": results of the French Observatoire in Internal Medicine Departments (FIMeD). Clin Genet. 2012;81:571-7.

11. Tuncbilek E, Ozguc M. Application of medical genetics in Turkey. Turk J Pediatr. 2007:49:353-9.

12. Rozenfeld PA, Romina C, Bioc RC, Lic NR, Kisinovsky I. The continuous challenge of diagnosing patients with Fabry disease in Argentina: genotype, experiences, anecdotes, and new learnings. J Inborn Errors Metab Screen. 2015. https://doi.org/10.1177/2326409815613806.

13. Nowak A, Mechtler TP, Hornemann T, Gawinecka J, Theswet E, Hilz MJ, et al. Genotype, phenotype and disease severity reflected by serum LysoGb3 levels in patients with Fabry disease. Mol Genet Metab. 2018;123:148-53.

14. Koca S, Tumer L, Okur I, Erten Y, Bakkaloglu S, Biberoglu G, et al. High incidence of co-existing factors significantly modifying the phenotype in patients with Fabry disease. Gene. 2019;687:280-8.

15. Kalkan Ucar S, Sozmen E, Duman S, Basci A, Coker M. Alpha-galactosidase A activity levels in Turkish male hemodialysis patients. Ther Apher Dial. 2012;16:560-5.

16. Okur I, Ezgu F, Biberoglu G, Tumer L, Erten Y, Isitman M, et al. Screening for Fabry disease in patients undergoing dialysis for chronic renal failure in Turkey: identification of new case with novel mutation. Gene. 2013;527:42-7.

17. El Dib R, Gomaa H, Ortiz A, Politei J, Kapoor A, Barreto F. Enzyme replacement therapy for Anderson-Fabry disease: a complementary overview of a Cochrane publication through a linear regression and a pooled analysis of proportions from cohort studies. PLOS ONE. 2017:12:e0173358.

18. Schiffmann R. Fabry disease. Pharmacol Ther. 2009;122:65-77.

19. Körver S, Vergouwe M, Hollak CEM, van Schaik IN, Langeveld M. Development and clinical consequences of white matter lesions in Fabry disease: a systematic review. Mol Genet Metab. 2018;125:205-16.

20. Neufeld EF. Lysosomal storage diseases. Annu Rev Biochem. 1991;60:257-80.

21. Hopkin RJ, Bissler J, Banikazemi M, Clarke L, Eng CM, Germain DP, et al. Characterization of Fabry disease in 352 pediatric patients in the Fabry registry. Pediatr Res. 2008;64:550-5.

22. Wilcox WR, Oliveira JP, Hopkin RJ, Ortiz A, Banikazemi M, FeldtRasmussen U, et al. Females with Fabry disease frequently have major organ involvement: lessons from the Fabry registry. Mol Genet Metab. 2008:93:112-28.

23. Schiffmann R, Hughes DA, Linthorst GE, Ortiz A, Svarstad E, Warnock $\mathrm{DG}$, et al. Screening, diagnosis, and management of patients with Fabry disease: conclusions from a "Kidney Disease: Improving Global Outcomes" (KDIGO) controversies conference. Kidney Int. 2017;91:284-93.

24. Schiffmann R, Warnock DG, Banikazemi M, Bultas J, Linthorst GE, Packman $S$, et al. Fabry disease: progression of nephropathy, and prevalence of cardiac and cerebrovascular events before enzyme replacement therapy. Nephrol Dial Transpl. 2009;24:2102-11.

25. MacDermot KD, Holmes A, Miners AH. Anderson-Fabry disease: clinical manifestations and impact of disease in a cohort of 60 obligate carrier females. J Med Genet. 2001;38:769-75.

26. Mehta A, Beck M, Eyskens F, Feliciani C, Kantola I, Ramaswami U, et al. Fabry disease: a review of current management strategies. QJM. 2010;103:641-59.

27. Meikle PJ, Hopwood JJ, Clague AE, Carey WF. Prevalence of lysosomal storage disorders. JAMA. 1999;281:249-54. 
28. Spada M, Pagliardini S, Yasuda M, Tukel T, Thiagarajan G, Sakuraba H, et al. High incidence of later-onset Fabry disease revealed by newborn screening. Am J Hum Genet. 2006;79:31-40.

29. Hwu WL, Chien YH, Lee NC, Chiang SC, Dobrovolny R, Huang AC, et al. Newborn screening for Fabry disease in Taiwan reveals a high incidence of the later-onset GLA mutation c.936+919G>A (IVS4+919G>A). Hum Mutat. 2009;30:1397-405.

30. Vedder AC, Linthorst GE, van Breemen MJ, Groener JE, Bemelman FJ, Strijland A, et al. The Dutch Fabry cohort: diversity of clinical manifestations and Gb3 levels. J Inherit Metab Dis. 2007;30:68-78.

31. Waldek S, Patel MR, Banikazemi M, Lemay R, Lee P. Life expectancy and cause of death in males and females with Fabry disease: findings from the Fabry registry. Genet Med. 2009;11:790-6.

32. Eng CM, Guffon N, Wilcox WR, Germain DP, Lee P, Waldek S, et al. Safety and efficacy of recombinant human alpha-galactosidase A replacement therapy in Fabry's disease. N Engl J Med. 2001;345:9-16.

33. Arends M, Wanner C, Hughes D, Mehta A, Oder D, Watkinson OT, et al. Characterization of classical and nonclassical Fabry disease: a multicenter study. J Am Soc Nephrol. 2017;28:1631-41.

34. Eng CM, Ashley GA, Burgert TS, Enriquez AL, D'Souza M, Desnick RJ. Fabry disease: thirty-five mutations in the alpha-galactosidase A gene in patients with classic and variant phenotypes. Mol Med. 1997;3:174-82.

35. Shabbeer J, Yasuda M, Benson SD, Desnick RJ. Fabry disease: identification of 50 novel alpha-galactosidase A mutations causing the classic phenotype and three-dimensional structural analysis of 29 missense mutations. Hum Genomics. 2006:2:297-309.

36. Wanner C, Arad M, Baron R, Burlina A, Elliott PM, Feldt-Rasmussen U, et al. European expert consensus statement on therapeutic goals in Fabry disease. Mol Genet Metab. 2018;124:189-203.

37. Germain DP, Arad M, Burlina A, Elliott PM, Falissard B, Feldt-Rasmussen $U$, et al. The effect of enzyme replacement therapy on clinical outcomes in female patients with Fabry disease: a systematic literature review by a European panel of experts. Mol Genet Metab. 2019;126:224-35.

38. Deegan PB, Baehner AF, Barba Romero MA, Hughes DA, Kampmann C, Beck M, et al. Natural history of Fabry disease in females in the Fabry outcome survey. J Med Genet. 2006:43:347-52.

39. Ortiz A, Germain DP, Desnick RJ, Politei J, Mauer M, Burlina A, et al. Fabry disease revisited: management and treatment recommendations for adult patients. Mol Genet Metab. 2018;123:416-27.

40. Germain DP. A new phenotype of Fabry disease with intermediate severity between the classical form and the cardiac variant. Contrib Nephrol. 2001;136:234-40.

41. Germain DP, Poenaru L. Fabry disease: identification of novel alphagalactosidase A mutations and molecular carrier detection by use of fluorescent chemical cleavage of mismatches. Biochem Biophys Res Commun. 1999;257:708-13.

42. Miller JJ, Kanack AJ, Dahms NM. Progress in the understanding and treatment of Fabry disease. Biochim Biophys Acta Gen Subj. 2020;1864:129437.

43. Kampmann C, Wiethoff CM, Whybra C, Baehner FA, Mengel E, Beck M. Cardiac manifestations of Anderson-Fabry disease in children and adolescents. Acta Paediatr. 2008:97:463-9.

44. Cabrera-Salazar MA, O'Rourke E, Charria-Ortiz G, Barranger JA. Radiological evidence of early cerebral microvascular disease in young children with Fabry disease. J Pediatr. 2005;147:102-5.

45. Ries M, Gupta S, Moore DF, Sachdev V, Quirk JM, Murray GJ, et al. Pediatric Fabry disease. Pediatrics. 2005;115:e344-55

46. Löhle M, Hughes D, Milligan A, Richfield L, Reichmann H, Mehta A, et al. Clinical prodromes of neurodegeneration in Anderson-Fabry disease. Neurology. 2015;84:1454-64.

47. Kiykim E, Sahin S, Zubarioglu T, Barut K, Adrovic A, Cansever MS, et al. Screening for Fabry disease in patients with juvenile systemic lupus erythematosus. Arch Rheumatol. 2020;35:7-12.

48. Huzmeli C, Candan F, Alaygut D, Bagci G, Akkaya L, Bagci B, et al. Prevalence of Fabry disease in Familial mediterranean fever patients from central Anatolia of Turkey. Biochem Genet. 2016;54:448-56.

49. Tümer L, Ezgü FS, Hasanoğlu A, Dalgiç B, Bakkaloğlu SA, Memiş L, et al. The co-existence of Fabry and celiac diseases: a case report. Pediatr Nephrol. 2004;19:679-81.
50. Thurberg BL, Rennke H, Colvin RB, Dikman S, Gordon RE, Collins AB, et al. Globotriaosylceramide accumulation in the Fabry kidney is cleared from multiple cell types after enzyme replacement therapy. Kidney Int. 2002;62:1933-46.

51. Ramaswami U, Najafian B, Schieppati A, Mauer M, Bichet DG. Assessment of renal pathology and dysfunction in children with Fabry disease. Clin J Am Soc Nephrol. 2010;5:365-70.

52. Gubler MC, Lenoir G, Grunfeld JP, Ulmann A, Droz D, Habib R. Early renal changes in hemizygous and heterozygous patients with Fabry's disease. Kidney Int. 1978;13:223-35.

53. Sessa A, Meroni M, Battini G, Maglio A, Brambilla PL, Bertella M, et al. Renal pathological changes in Fabry disease. J Inherit Metab Dis. 2001:24:66-70.

54. Tondel C, Bostad L, Hirth A, Svarstad E. Renal biopsy findings in children and adolescents with Fabry disease and minimal albuminuria. Am J Kidney Dis. 2008;51:767-76.

55. Ortiz A, Oliveira JP, Waldek S, Warnock DG, Cianciaruso B, Wanner C. Nephropathy in males and females with Fabry disease: cross-sectional description of patients before treatment with enzyme replacement therapy. Nephrol Dial Transplant. 2008;23:1600-7.

56. Branton MH, Schiffmann R, Sabnis SG, Murray GJ, Quirk JM, Altarescu $G$, et al. Natural history of Fabry renal disease: influence of alpha-galactosidase $\mathrm{A}$ activity and genetic mutations on clinical course. Medicine (Baltimore). 2002;81:122-38.

57. West M, Nicholls K, Mehta A, Clarke JT, Steiner R, Beck M, et al. Agalsidase alfa and kidney dysfunction in Fabry disease. J Am Soc Nephrol. 2009:20:1132-9.

58. MacDermot J, MacDermot KD. Neuropathic pain in AndersonFabry disease: pathology and therapeutic options. Eur J Pharmacol. 2001;429:121-5.

59. Froissart M, Benistan K, Germain DP. Functional renal investigation in Fabry disease. Presse Med. 2007;36:36-42.

60. Eng CM, Germain DP, Banikazemi M, Warnock DG, Wanner C, Hopkin RJ, et al. Fabry disease: guidelines for the evaluation and management of multiorgan system involvement. Genet Med. 2006;8:539-48.

61. Wanner C, Oliveira JP, Ortiz A, Mauer M, Germain DP, Linthorst GE, et al. Prognostic indicators of renal disease progression in adults with Fabry disease: natural history data from the Fabry registry. Clin J Am Soc Nephrol. 2010;5:2220-8.

62. Masson C, Cissé I, Simon V, Insalaco P, Audran M. Fabry disease: a review. Joint Bone Spine. 2004;71:381-3.

63. Mena Rodríguez AL, Soto Abraham MV, Valdespino Vázquez MY, de León Garza B. Histopathological findings in renal biopsies in AndersonFabry disease. Case series. Rev Med Hosp Gen Mex. 2018;81:243-7.

64. Albay D, Adler SG, Philipose J, Calescibetta CC, Romansky SG, Cohen $\mathrm{AH}$. Chloroquine-induced lipidosis mimicking Fabry disease. Mod Pathol. 2005;18:733-8.

65. Kampmann C, Baehner F, Whybra C, Martin C, Wiethoff CM, Ries M, et al. Cardiac manifestations of Anderson-Fabry disease in heterozygous females. J Am Coll Cardiol. 2002;40:1668-74.

66. Patel MR, Cecchi F, Cizmarik M, Kantola I, Linhart A, Nicholls K, et al. Cardiovascular events in patients with Fabry disease natural history data from the Fabry registry. J Am Coll Cardiol. 2011:57:1093-9.

67. Patel V, O'Mahony C, Hughes D, Rahman MS, Coats C, Murphy E, et al. Clinical and genetic predictors of major cardiac events in patients with Anderson-Fabry disease. Heart. 2015;101:961-6.

68. Kampmann C, Baehner FA, Whybra C, Bajbouj M, Baron K, Knuf M, et al. The right ventricle in Fabry disease. Acta Paediatr Suppl. 2005;94:15-8.

69. Weidemann F, Niemann M, Störk S, Breunig F, Beer M, Sommer C, et al. Long-term outcome of enzyme-replacement therapy in advanced Fabry disease: evidence for disease progression towards serious complications. J Intern Med. 2013;274:331-41.

70. Takenaka T, Teraguchi H, Yoshida A, Taguchi S, Ninomiya K, Umekita Y, et al. Terminal stage cardiac findings in patients with cardiac Fabry disease: an electrocardiographic, echocardiographic, and autopsy study. J Cardiol. 2008;51:50-9.

71. Weidemann F, Breunig F, Beer M, Sandstede J, Störk S, Voelker W, et al. The variation of morphological and functional cardiac manifestation in Fabry disease: potential implications for the time course of the disease. Eur Heart J. 2005;26:1221-7. 
72. Elliott PM, Anastasakis A, Borger MA, Borggrefe M, Cecchi F, Charron P, et al. 2014 ESC Guidelines on diagnosis and management of hypertrophic cardiomyopathy: the Task Force for the diagnosis and management of hypertrophic cardiomyopathy of the European Society of Cardiology (ESC). Eur Heart J. 2014;35:2733-79.

73. Hsu TR, Hung SC, Chang FP, Yu WC, Sung SH, Hsu CL, et al. Later onset Fabry disease, cardiac damage progress in silence: experience with a highly prevalent mutation. J Am Coll Cardiol. 2016;68:2554-63.

74. Deva DP, Hanneman K, Li Q, Ng MY, Wasim S, Morel C, et al. Cardiovascular magnetic resonance demonstration of the spectrum of morphological phenotypes and patterns of myocardial scarring in Anderson-Fabry disease. J Cardiovasc Magn Reson. 2016;18:14.

75. Thompson RB, Chow K, Khan A, Chan A, Shanks M, Paterson l, et al. $\mathrm{T}_{1}$ mapping with cardiovascular MRI is highly sensitive for Fabry disease independent of hypertrophy and sex. Circ Cardiovasc Imaging. 2013;6:637-45.

76. Sado DM, White SK, Piechnik SK, Banypersad SM, Treibel T, Captur G, et al. Identification and assessment of Anderson-Fabry disease by cardiovascular magnetic resonance noncontrast myocardial T1 mapping. Circ Cardiovasc Imaging. 2013;6:392-8

77. Seydelmann N, Wanner C, Störk S, Ertl G, Weidemann F. Fabry disease and the heart. Best Pract Res Clin Endocrinol Metab. 2015;29:195-204.

78. Ramaswami U, Whybra C, Parini R, Pintos-Morell G, Mehta A, SunderPlassmann $\mathrm{G}$, et al. Clinical manifestations of Fabry disease in children: data from the Fabry Outcome Survey. Acta Paediatr. 2006;95:86-92.

79. Ries M, Ramaswami U, Parini R, Lindblad B, Whybra C, Willers I, et al. The early clinical phenotype of FD: a study on 35 European children and adolescents. Eur J Pediatr. 2003;162:767-72.

80. Mehta A, Ricci R, Widmer U, Dehout F, de Lorenzo AG, Kampmann C, et al. Fabry disease defined: baseline clinical manifestations of 366 patients in the Fabry Outcome Survey. Eur J Clin Invest. 2004;34:236-42.

81. Uceyler N, Ganendiran S, Kramer D, Sommer C. Characterization of pain in Fabry disease. Clin J Pain. 2014;30:915-20.

82. Charrow J. A 14-year-old boy with pain in hands and feet. Pediatr Ann. 2009:38:190-2.

83. Hilz MJ, Stemper B, Kolodny EH. Lower limb cold exposure induces pain and prolonged small fiber dysfunction in Fabry patients. Pain. 2000;84:361-5.

84. Naleschinski D, Arning K, Baron R. Fabry disease: pain doctors have to find the missing ones. Pain. 2009;145:10-1.

85. El-Abassi R, Singhal D, England JD. Fabry's disease. J Neurol Sci. 2014;344:5-19.

86. Saip S, Uluduz D, Erkol G. Fabry disease mimicking multiple sclerosis. Clin Neurol Neurosurg. 2007;109:361-3.

87. Kang WH, Chun SI, Lee S. Generalized anhidrosis associated with Fabry's disease. J Am Acad Dermatol. 1987;17:883-7.

88. Orteu CH, Jansen T, Lidove O, Jaussaud R, Hughes DA, Pintos-Morell G, et al. Fabry disease and the skin: data from FOS, the Fabry Outcome Survey. Br J Dermatol. 2007;157:331-7.

89. Gupta SN, Ries M, Murray GJ, Quirk JM, Brady RO, Lidicker JR, et al. Skinimpedance in Fabry disease: a prospective, controlled, non-randomized clinical study. BMC Neurol. 2008;8:41.

90. Møller AT, Bach FW, Feldt-Rasmussen U, Rasmussen AK, Hasholt L, Sommer C, et al. Autonomic skin responses in females with Fabry disease. J Peripher Nerv Syst. 2009;14:159-64.

91. Ellaway PH, Kuppuswamy A, Nicotra A, Mathias CJ. Sweat production and the sympathetic skin response: improving the clinical assessment of autonomic function. Auton Neurosci. 2010;155:109-14.

92. Germain DP, Avan P, Chassaing A, Bonfils P. Patients affected with Fabry disease have an increased incidence of progressive hearing loss and sudden deafness: an investigation of twenty-two hemizygous male patients. BMC Med Genet. 2002;3:10.

93. Sakurai Y, Kojima H, Shiwa M, Ohashi T, Eto Y, Moriyama H. The hearing status in 12 female and 15 male Japanese Fabry patients. Auris Nasus Larynx. 2009;36:627-32.

94. Conti G, Sergi B. Auditory and vestibular findings in Fabry disease: a study of hemizygous males and heterozygous females. Acta Paediatr Suppl. 2003;92:33-7.

95. Kiykim E, Kaya M, Dincer MT, Bakir A, Alagoz S, Aktuglu Zeybek A, et al. Reflex decay test can reveal ear involvement in Fabry disease. Ear Hear. 2021;42:1351-7.
96. Hoffmann B, Schwarz M, Mehta A, Keshav S. Gastrointestinal symptoms in 342 patients with Fabry disease: prevalence and response to enzyme replacement therapy. Clin Gastroenterol Hepatol. 2007:5:1447-53.

97. Buda P, Książyk J, Tylki-Szymanska A. Gastroenterological complications of Anderson-Fabry disease. Curr Pharm Des. 2013;19:6009-13.

98. Kolodny E, Fellgiebel A, Hilz MJ, Sims K, Caruso P, Phan TG, et al. Cerebrovascular involvement in Fabry disease: current status of knowledge. Stroke. 2015;46:302-13.

99. Sheng S, Wu L, Nalleballe K, Sharma R, Brown A, Ranabothu S, et al. Fabry's disease and stroke: effectiveness of enzyme replacement therapy (ERT) in stroke prevention, a review with meta-analysis. J Clin Neurosci. 2019;65:83-6.

100. Lanthier S, Saposnik G, Lebovic G. Prevalence of Fabry disease and outcomes in young Canadian patients with cryptogenic ischemic cerebrovascular events. Stroke. 2017;48:1766-72.

101. Rolfs A, Martus P, Heuschmann PU. Protocol and methodology of the Stroke in Young Fabry patients (sifap1) study: a prospective multicenter European study of 5,024 young stroke patients aged 18-55 years. Cerebrovasc Dis. 2011;31:253-62.

102. Rost NS, Cloonan L, Kanakis AS, Fitzpatrick KM, Azzariti DR, Clarke V, et al. Determinants of white matter hyperintensity burden in patients with Fabry disease. Neurology. 2016;86:1880-6.

103. Fellgiebel A, Gartenschläger M, Wildberger K, Scheurich A, Desnick RJ, Sims K. Enzyme replacement therapy stabilized white matter lesion progression in Fabry disease. Cerebrovasc Dis. 2014;38:448-56.

104. Manara R, Carlier RY, Righetto S, Citton V, Locatelli G, Colas F, et al. Basilar artery changes in Fabry disease. Am J Neuroradiol. 2017;38:531-6.

105. Sims K, Politei J, Banikazemi M, Lee P. Stroke in Fabry disease frequently occurs before diagnosis and in the absence of other clinical events: natural history data from the Fabry Registry. Stroke. 2009;40:788-94.

106. Jardim L, Vedolin L, Schwartz IV, Burin MG, Cecchin C, Kalakun L, et al. CNS involvement in Fabry disease: clinical and imaging studies before and after 12 months of enzyme replacement therapy. J Inherit Metab Dis. 2004;27:229-40.

107. Fellgiebel A, Muller MJ, Mazanek M, Baron K, Beck M, Stoeter P. White matter lesion severity in male and female patients with Fabry disease. Neurology. 2005;65:600-2.

108. Moore DF, Ye F, Schiffmann R, Butman JA. Increased signal intensity in the pulvinar on T1-weighted images: a pathognomonic MR imaging sign of Fabry disease. AJNR Am J Neuroradiol. 2003;24:1096-101.

109. Takanashi J, Barkovich AJ, Dillon WP, Sherr EH, Hart KA, Packman S. T1 hyperintensity in the pulvinar: key imaging feature for diagnosis of Fabry disease. AJNR Am J Neuroradiol. 2003;24:916-21.

110. Burlina AP, Manara R, Caillaud C, Laissy JP, Severino M, Klein I, et al. The pulvinar sign: frequency and clinical correlations in Fabry disease. J Neurol. 2008;255:738-44.

111. Colomba P, Zizzo C, Alessandro R, Cammarata G, Scalia S, Giordano A, et al. Fabry disease and multiple sclerosis misdiagnosis: the role of family history and neurological signs. Oncotarget. 2018;9:7758-62.

112. Burlina A, Politei J. The central nervous system involvement in Fabry disease: a review. J Inborn Err Metab Screening. 2016:4:1-7.

113. Bot JC, Barkhof F, Lycklama à Nijeholt G, van Schaardenburg D, Voskuyl $\mathrm{AE}, \mathrm{Ader} \mathrm{HJ}$, et al. Differentiation of multiple sclerosis from other inflammatory disorders and cerebrovascular disease: value of spinal MR imaging. Radiology. 2002;223:46-56.

114. Samiy N. Ocular features of Fabry disease: diagnosis of a treatable lifethreatening disorder. Surv Ophthalmol. 2008;53:416-23.

115. Pitz S, Kalkum G, Arash L, Karabul N, Sodi A, Larroque S, et al. Ocular signs correlate well with disease severity and genotype in Fabry disease. PLOS ONE. 2015;10:e0120814.

116. Nguyen TT, Gin T, Nicholls K, Low M, Galanos J, Crawford A. Ophthalmological manifestations of Fabry disease: a survey of patients at the Royal Melbourne Fabry disease treatment centre. Clin Exp Ophthalmol. 2005;33:164-8.

117. Sodi A, loannidis AS, Mehta A, Davey C, Beck M, Pitz S. Ocular manifestations of Fabry's disease: data from the Fabry Outcome Survey. Br J Ophthalmol. 2007;91:210-4.

118. Falke K, Buttner A, Schittkowski M, Stachs O, Kraak R, Zhivov A, et al. The microstructure of cornea verticillata in Fabry disease and 
amiodarone-induced keratopathy: a confocal laser-scanning microscopy study. Graefes Arch Clin Exp Ophthalmol. 2009;247:523-34.

119. Boutouyrie P, Laurent S, Laloux B, Lidove O, Grunfeld JP, Germain DP. Noninvasive evaluation of arterial involvement in patients affected with Fabry disease. J Med Genet. 2001;38:629-31.

120. Orssaud C, Dufier J, Germain DP. Ocular manifestations in Fabry disease: a survey of 32 hemizygous male patients. Ophthalmic Genet. 2003;24:129-39.

121. Ersoz MG, Ture G. Cilioretinal artery occlusion and anterior ischemic optic neuropathy as the initial presentation in a child female carrier of Fabry disease. Int Ophthalmol. 2018;38:771-3.

122. Allen LE, Cosgrave EM, Kersey JP, Ramaswami U. Fabry disease in children: correlation between ocular manifestations, genotype and systemic clinical severity. Br J Ophthalmol. 2010;94:1602-5.

123. Rudich DS, Curcio CA, Wasserstein M, Brodie SE. Inner macular hyperreflectivity demonstrated by optical coherence tomography in niemannpick disease. JAMA Ophthalmol. 2013;131:1244-6.

124. Shrier EM, Barr CC, Grabowski GA. Vitreous opacities and retinal vascular abnormalities in Gaucher disease. Arch Ophthalmol. 2004;122:1395-8.

125. Zampetti A, Orteu CH, Antuzzi D, Bongiorno MR, Manco S, Gnarra M, et al. Angiokeratoma: decision-making aid for the diagnosis of Fabry disease. Br J Dermatol. 2012;166:712-20.

126. Dhoat S, Orteu CH, Navarro C, Lidove O, Jamsen T, Clarke J. Patients with Fabry disease with cutaneous vascular lesions have higher disease severity scores and more multisystem involvement: data from 1354 patients registered on FOS, the Fabry outcome survey. Br J Dermatol. 2009:161(Suppl 1):45.

127. Shelley ED, Shelley WB, Kurczynski TW. Painful fingers, heat intolerance, and telangiectases of the ear: easily ignored childhood signs of Fabry disease. Pediatr Dermatol. 1995;12:215-9.

128. Cox-Brinkman J, Vedder A, Hollak C, Richfield L, Mehta A, Orteu K, et al. Three-dimensional face shape in Fabry disease. Eur J Hum Genet. 2007;15:535-42.

129. Mohrenschlager M, Braun-Falco M, Ring J, Abeck D. Fabry disease: recognition and management of cutaneous manifestations. Am J Clin Dermatol. 2003:4:189-96.

130. Navarro C, Teijeira S, Dominguez C, Fernandez JM, Rivas E, Fachal C, et al. Fabry disease: an ultrastructural comparative study of skin in hemizygous and heterozygous patients. Acta Neuropathol. 2006;111:178-85.

131. Martins AM, D'Almeida V, Kyosen SO, Takata ET, Delgado AG, Gonçalves $\mathrm{AM}$, et al. Guidelines to diagnosis and monitoring of Fabry disease and review of treatment experiences. J Pediatr. 2009;155(4 Suppl):S19-31.

132. Grunfeld JP. How to improve the early diagnosis of Fabry's disease? Kidney Int. 2003;64:1136-7.

133. David G, Warnock DG, Valbuena C, West M, Oliveira JP. Renal manifestations of Fabry disease. In: Elstein D, Altarescu G, Beck M, editors. Fabry disease. Springer; 2010. p. 225.

134. Laney DA, Bennett RL, Clarke V, Fox A, Hopkin RJ, Johnson J, et al. Fabry disease practice guidelines: recommendations of the National Society of genetic counselors. J Genet Couns. 2013;22:555-64.

135. López RM. Treatment in Fabry disease. Rev Clin Esp. 2018;218:489-95.

136. Smid BE, van der Tol $L$, Cecchi F, Elliott PM, Hughes DA, Linthorst GE, et al. Uncertain diagnosis of Fabry disease: consensus recommendation on diagnosis in adults with left ventricular hypertrophy and genetic variants of unknown significance. Int J Cardiol. 2014;177:400-8.

137. Schaefer E, Mehta A, Gal A. Genotype and phenotype in Fabry disease: analysis of the Fabry Outcome Survey. Acta Paediatr Suppl. 2005;94:87-92.

138. Braga MC, Fonseca FLA, Marins MM, Gomes CP, Bacci MR, Martins AM, et al. Evaluation of Beta 2-microglobulin, cystatin C, and lipocalin-2 as renal biomarkers for patients with Fabry disease. Nephron. 2019;143:217-27.

139. Olivera-González S, Josa-Laorden C, Torralba-Cabeza MA. The pathophysiology of Fabry disease. Rev Clin Esp. 2018;218:22-8.

140. Waldek S, Feriozzi S. Fabry nephropaty: a review - how can weoptimize the management of Fabry nephropaty. BMC Nephrol. 2014;15:72-84.

141. Carnicer-Cáceres C, Arranz-Amo JA, Cea-Arestin C, Camprodon-Gomez M, Moreno-Martinez D, Lucas-Del-Pozo S, et al. Biomarkers in Fabry disease implications for clinical diagnosis and follow-up. J Clin Med. 2021:10:1664.
142. Rombach SM, Dekker N, Bouwman MG, Linthorst GE, Zwinderman AH, Wijburg FA, et al. Plasma globotriaosylsphingosine: diagnostic value and relation to clinical manifestations of Fabry disease. Biochim Biophys Acta. 2010;180:741-8

143. Aerts JM, Groener JE, Kuiper S, Donker-Koopman WE, Strijland A, Ottenhoff $\mathrm{R}$, et al. Elevated globotriaosylsphingosine is a hallmark of Fabry disease. Proc Natl Acad Sci USA. 2008;105:2812-7.

144. Sakuraba H, Togawa T, Tsukimura T, Kato H. Plasma lyso-Gb3: a biomarker for monitoring fabry patients during enzyme replacement therapy. Clin Exp Nephrol. 2018;22:843-9.

145. Shu L, Vivekanandan-Giri A, Pennathur S, Smid BE, Aerts JM, Hollak CE, et al. Establishing 3-nitrotyrosine as a biomarkerfor the vasculopathy of Fabry disease. Kidney Int. 2014;86:58-66.

146. Trimarchi H, Canzonieri R, Schiel A, Costales-Collaguazo C, Politei J, Stern $\mathrm{A}$, et al. Increased urinary CD80 excretionand podocyturia in Fabry disease. JTransl Med. 2016;13:289.

147. Brakch N, Dormond O, Bekri S, Golshayan D, Correvon M, Mazzolai L, et al. Evidence for a role of sphingosine-1 phosphate in cardiovascular remodelling in Fabry disease. Eur Heart J. 2010;31:67-76.

148. Bennett RL, Hart KA, O'Rourke E, Barranger JA, Johnson J, MacDermot $\mathrm{KD}$, et al. Fabry disease in genetic counseling practice: recommendations of the National Society of genetic counselors. J Genet Couns. 2002;11:121-46.

149. Laney DA, Fernhoff PM. Diagnosis of Fabry disease via analysis of family history. J Genet Couns. 2008;17:79-83.

150. van der Tol L, Smid BE, Poorthuis BJ, Biegstraaten M, Deprez RH, Linthorst $\mathrm{GE}$, et al. A systematic review on screening for Fabry disease: prevalence of individuals with genetic variants of unknown significance. J Med Genet. 2014;51:1-9.

151. Matern D, Gavrilov D, Oglesbee D, Raymond K, Rinaldo P, Tortorelli S. Newborn screening for lysosomal storage disorders. Semin Perinatol. 2015;39:206-16.

152. van der Tol L, Cassiman D, Houge G, Janssen MC, Lachmann RH, Linthorst GE, et al. Uncertain diagnosis of fabry disease in patients with neuropathic pain, angiokeratoma or cornea verticillata: consensus on the approach to diagnosis and follow-up. JIMD Rep. 2014;17:83-90.

153. Thomas AS, Mehta AB. Difficulties and barriers in diagnosing FD: what can be learnt from the literature? Expert Opin Med Diagn. 2013;7:589-99.

154. Lenders M, Duning T, Schelleckes M, Schmitz B, Stander S, Rolfs A, et al. Multifocal white matter lesions associated with the D313Y mutation of the alpha-galactosidase A gene. PLOS ONE. 2013:8:e55565.

155. Niemann M, Rolfs A, Giese A, Mascher H, Breunig F, Ertl G, et al. LysoGb3 indicates that the alpha-galactosidase A mutation D313Y is not clinically relevant for Fabry disease. JIMD Rep. 2013;7:99-102.

156. Tolouian $\mathrm{R}$, Salameh $\mathrm{H}$. Treat the patient not the lab value. NDT Plus. 2010;3:81-3.

157. Smid BE, Hollak CE, Poorthuis BJ, van den Bergh Weerman MA, Florquin $\mathrm{S}$, Kok WE, et al. Diagnostic dilemmas in Fabry disease: a case series study on GLA mutations of unknown clinical significance. Clin Genet. 2015:88:161-6.

158. Onay H, Bolat H, Kilıç Yıldııım G, Kose E, Ucar SK, Asikovalı S, et al. Analysis of the alpha galactosidase gene: mutation profile and description of two novel mutations with extensive literature review in Turkish population. J Pediatr Endocrinol Metab. 2020;33:1245-50.

159. Felis A, Whitlow M, Kraus A, Warnock DG, Wallace E. Current and investigational therapeutics for Fabry disease. Kidney Int Rep. 2019;5:407-13.

160. Lee K, Jin X, Zhang K, Copertino L, Andrews L, Baker-Malcolm J, et al. A biochemical and pharmacological comparison of enzyme replacement therapies for the glycolipid storage disorder Fabry disease. Glycobiology. 2003;13:305-13.

161. Warnock DG, Mauer M. Fabry disease: dose matters. J Am Soc Nephrol. 2014;25:653-5.

162. Desnick RJ. Enzyme replacement therapy for Fabry disease: lessons from two alpha-galactosidase A orphan products and one FDA approval. Expert Opin Biol Ther. 2004:4:1167-76.

163. Pisani A, Visciano B, Roux GD, Sabbatini M, Porto C, Parenti G, et al. Enzyme replacement therapy in patients with Fabry disease: state of the art and review of the literature. Mol Genet Metab. 2012;107:267-75. 
164. Mehta A, Beck M, Elliott P, Giugliani R, Linhart A, Sunder-Plassmann G, et al. Enzyme replacement therapy with agalsidase alfa in patients with Fabry's disease: an analysis of registry data. Lancet. 2009;374:1986-96.

165. Hughes DA, Elliott PM, Shah J, Zuckerman J, Coghlan G, Brookes J, et al. Effects of enzyme replacement therapy on the cardiomyopathy of Anderson-Fabry disease: a randomised, double-blind, placebocontrolled clinical trial of agalsidase alfa. Heart. 2008;94:153-8.

166. Feriozzi S, Hughes DA. New drugs for the treatment of Anderson-Fabry disease. J Nephrol. 2021;34:221-30.

167. Chen Q, Davis KR. The potential of plants as a system for the development and production of human biologics. F1000Res. 2016;5:912.

168. Kizhner T, Azulay Y, Hainrichson M, Tekoah Y, Arvatz G, Shulman A, et al. Characterization of a chemically modified plant cell culture expressed human alpha-galactosidase-A enzyme for treatment of Fabry disease. Mol Genet Metab. 2015;114:259-67.

169. Schiffmann R, Goker-Alpan O, Holida M, Giraldo P, Barisoni L, Colvin $\mathrm{RB}$, et al. Pegunigalsidase alfa, a novel PEGylated enzyme replacement therapy for Fabry disease, provides sustained plasma concentrations and favorable pharmacodynamics: a 1-year phase 1/2 clinical trial. J Inherit Metab Dis. 2019;42:534-44.

170. Hopkin RJ, Jefferies JL, Laney DA, Lawson VH, Mauer M, Taylor MR, et al. Fabry pediatric expert panel. The management and treatment of children with Fabry disease: A United States-based perspective. Mol Genet Metab. 2016;117:104-13.

171. Lenders M, Brand E. Fabry disease: the current treatment landscape. Drugs. 2021;81:635-45.

172. Motabar O, Sidransky E, Goldin E, Zheng W. Fabry disease-current treatment and new drug development. Curr Chem Genomics. 2010;4:50-6.

173. Germain DP, Hughes DA, Nicholls K, Bichet DG, Giugliani R, Wilcox WR, et al. Treatment of Fabry's disease with the pharmacologic chaperone migalastat. N Engl J Med. 2016;375:545-55.

174. Hughes DA, Nicholls K, Shankar SP, Sunder-Plassmann G, Koeller D, Nedd K, et al. Oral pharmacological chaperone migalastat compared with enzyme replacement therapy in Fabry disease: 18-month results from the randomised phase III ATTRACT study. J Med Genet. 2017:54:288-96.

175. Riccio E, Zanfardino M, Ferreri L, Santoro C, Cocozza S, Capuano I, et al. Switch from enzyme replacement therapy to oral chaperone migalastat for treating fabry disease: real-life data. Eur J Hum Genet. 2020;28:1662-8.

176. McCafferty EH, Scott L. Migalastat: a review in Fabry disease. Drugs. 2019;79:543-54

177. Welford RWD, Mühlemann A, Garzotti M, Rickert V, Groenen PMA, Morand O, et al. Glucosylceramide synthase inhibition with lucerastat lowers globotriaosylceramide and lysosome staining in cultured fibroblasts from Fabry patients with different mutation types. Hum Mol Genet. 2018;27:3392-403.

178. van der Veen SJ, Hollak CEM, van Kuilenburg ABP, Langeveld M. Developments in the treatment of Fabry disease. J Inherit Metab Dis. 2020;43:908-21.

179. Domm JM, Wootton SK, Medin JA, West ML. Gene therapy for Fabry disease: progress, challenges, and outlooks on gene-editing. Mol Genet Metab. 2021;134:117-31.

180. Eng CM, Germain DP, Banikazemi M, Warnock DG, Wanner C, Hopkin RJ, et al. Fabry disease: guidelines for the evaluation and management of multi-organ system involvement. Genet Med. 2006;8:539-48.

181. Biegstraaten M, Arngrímsson R, Barbey F, Boks L, Cecchi F, Deegan PB, et al. Recommendations for initiation and cessation of enzyme replacement therapy in patients with Fabry disease: the European Fabry Working Group consensus document. Orphanet J Rare Dis. 2015;10:36.

182. Fernández P, Fernández SO, Gonzalez JGM, FernándezT, Fernández CC, Fernández SP. Enzyme replacement therapy in pregnant women with Fabry disease: a case series. JIMD Rep. 2019;45:77-81.

183. Senocak Tasci E, Bicik Z. Safe and successful treatment with agalsidase beta during pregnancy in Fabry disease. Iran J Kidney Dis. 2015;9:406-8.

\section{Publisher's Note}

Springer Nature remains neutral with regard to jurisdictional claims in published maps and institutional affiliations.

Ready to submit your research? Choose BMC and benefit from:

- fast, convenient online submission

- thorough peer review by experienced researchers in your field

- rapid publication on acceptance

- support for research data, including large and complex data types

- gold Open Access which fosters wider collaboration and increased citations

- maximum visibility for your research: over $100 \mathrm{M}$ website views per year

At BMC, research is always in progress.

Learn more biomedcentral.com/submissions 